\title{
Online Appendix: Macroeconomic Effects of Bankruptcy and Foreclosure Policies
}

Kurt Mitman

January 27, 2016

\section{Full Specification of the Household Problem}

For completeness, I include here the full specification of the household problem (including value functions already discussed in the main text).

$$
\begin{aligned}
& V_{G}^{o w n}\left(b, h, m, p_{h}, \omega, y, z, \theta=0\right)=
\end{aligned}
$$

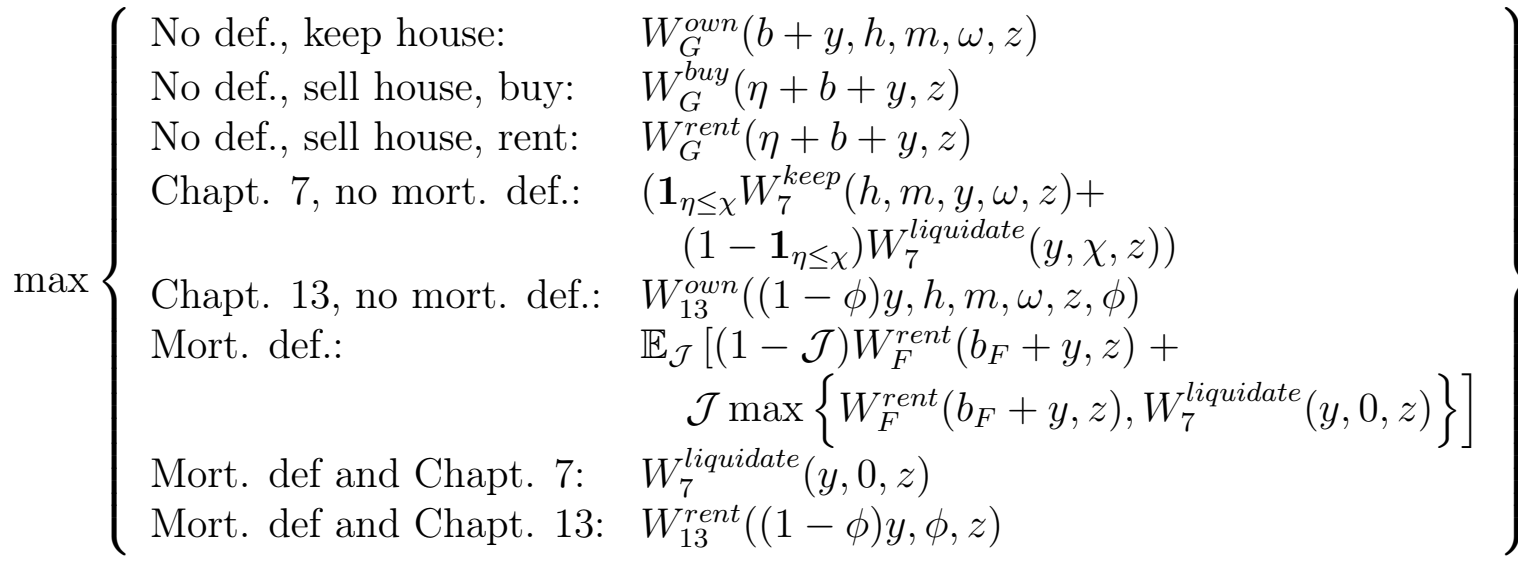$$
V_{G}^{\text {own }}\left(b, h, m, p_{h}, \omega, y, z, \theta=1\right)=
$$

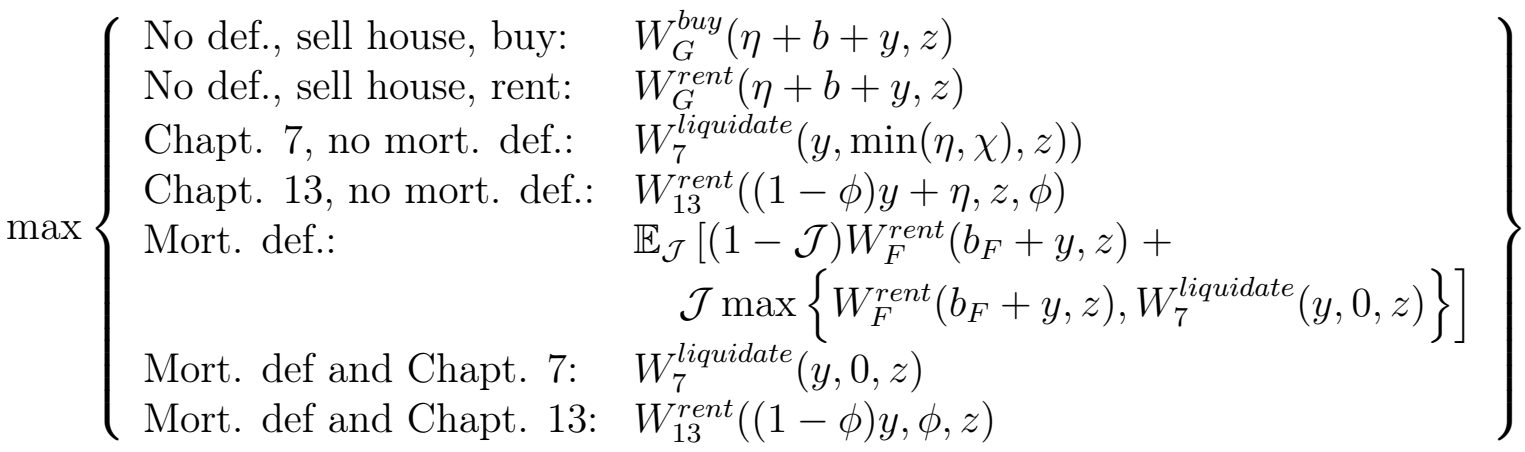


where $W_{G}^{\text {own }}$ is the value of not defaulting on either debt, nor selling one's home, $W_{G}^{\text {buy }}$ and $W_{G}^{r e n t}$ are the value of not defaulting, selling one's home, and buying a new home or becoming a renter, respectively ${ }^{1}, \mathbf{1}_{\eta \leq \chi}$ is an indicator if the household has only exempt home equity, $W_{7}^{\text {keep }}$ and $W_{7}^{\text {liquidate }}$ are the values of filing for Chapter 7 bankruptcy without and with having to liquidate, respectively, $W_{13}^{\text {own }}$ is the value of filing Chapter 13 bankruptcy, $W_{F}^{r e n t}$ is the value of defaulting on the mortgage $\left(\mathbb{E}_{\mathcal{J}}\right.$ is the expectation over a deficiency judgment if the household goes in to foreclosure), and $W_{7}^{\text {rent }}$ is the value of being foreclosed upon and filing for Chapter 7 bankruptcy 2 . The discrete decision is similar for a household hit by the moving shock, however it no longer has the option to keep the house. In addition, when hit by the moving shock if the household files for Chapter 7 and 13 bankruptcies, the house is liquidated. That value function can be found in the Online Appendix.

A homeowner that keeps its home and does not default on (any) debt solves the following program:

$$
\begin{gathered}
W_{G}^{\text {own }}(a, h, m, \omega, z)=\max _{c, p_{h} h \geq m^{\prime} \geq 0, b^{\prime}}\left\{U(c, h)+\beta \mathbb{E}_{p_{h}^{\prime}, \omega^{\prime}, y^{\prime}, z^{\prime}, \theta^{\prime} \mid \omega, z} V_{G}^{\text {own }}\left(b^{\prime}, h, m^{\prime}, p_{h}^{\prime}, \omega^{\prime}, y^{\prime}, z^{\prime}, \theta^{\prime}\right)\right\} \\
\text { subj. to } \quad c+m\left(1+r_{m}\right)-m^{\prime} Q_{m}+b^{\prime} q_{b}\left(b^{\prime}, h, m^{\prime}, \omega, z, G\right)-\mu_{h} p_{h} h \leq a \\
\text { where: } \quad Q_{m}= \begin{cases}q_{m}\left(b^{\prime}, h, m^{\prime}, \omega, z, G\right) & \text { if } m^{\prime}>m \\
1 & \text { if } m^{\prime} \leq m .\end{cases}
\end{gathered}
$$

When the homeowner makes the interest (and possible principal) payment $Q_{m}$ takes the value of one, whereas if the household wants a larger principal balance it must refinance its mortgage, which is represented by $Q_{m}=q_{m}$, the price which takes into account the default risk of taking the new mortgage. By assumption, households can only originate mortages with principal balances less than the current value of the home 3

A household with good credit that decides to buy a home, chooses non-durable consumption, the size of house, mortgage and bonds, and solves the following program:

$$
\begin{aligned}
& W_{G}^{\text {buy }}(a, z)=\max _{c, h^{\prime} \in \mathcal{H}, h^{\prime} \geq m^{\prime} \geq 0, b^{\prime}}\left\{U\left(c, h^{\prime}\right)+\beta \mathbb{E}_{p_{h}^{\prime}, \omega^{\prime}, y^{\prime}, z^{\prime}, \theta^{\prime} \mid \omega, z} V_{G}^{\text {own }}\left(b^{\prime}, h^{\prime}, m^{\prime}, p_{h}^{\prime}, \omega^{\prime}, y^{\prime}, z^{\prime}, \theta^{\prime}\right)\right\} \\
& \text { subj. to } \quad c+p_{h} h^{\prime}-m^{\prime} q_{m}\left(b^{\prime}, h^{\prime}, m^{\prime}, \omega, z, G\right)+b^{\prime} q_{b}\left(b^{\prime}, h, m^{\prime}, \omega, z, G\right)-\mu_{h} p_{h} h^{\prime} \leq a \\
& \text { where: } p_{h}=1, \omega=0
\end{aligned}
$$

Since all house price risk is idiosyncratic when households buy a new home the price is set to 1 , the unconditional mean of the process.

A household with good credit that decides to be a renter only chooses between nondurable consumptions and bond holdings, and solves the following program:

\footnotetext{
${ }^{1}$ Note that the timing assumption is such that these households can immediately buy a new home and live in it during the period.

${ }^{2}$ The assumption here is that Chapter 7 bankruptcy is a worse credit event than foreclosure, and thus the credit state evolves to the more serious default.

${ }^{3}$ This does not preclude households from having negative equity on existing mortgages, they simply cannot originate new mortgages with negative equity
} 


$$
\begin{aligned}
& W_{G}^{r e n t}(a, z)=\max _{c, b^{\prime}}\left\{U(c, \underline{h})+\beta \mathbb{E}_{y^{\prime}, z^{\prime} \mid z} V_{G}^{r e n t}\left(b^{\prime}, y^{\prime}, z^{\prime}\right)\right\} \\
& \text { subj. to } \quad c+p_{r} \underline{h}+b^{\prime} q_{b}\left(b^{\prime}, z, G\right) \leq a
\end{aligned}
$$

A household that filed for Chapter 7 bankruptcy in the current period and kept its home makes an interest payment (if it has a mortgage) and consumes the rest of its income:

$$
\begin{gathered}
W_{7}^{\text {keep }}(h, m, y, \omega, z)=U(c, h)+\beta \mathbb{E}_{p_{h}^{\prime}, \omega^{\prime}, y^{\prime}, z^{\prime}, \theta^{\prime} \mid \omega, z} V_{7}^{\text {own }}\left(0, h, m, p_{h}^{\prime}, \omega^{\prime}, y^{\prime}, z^{\prime}, \theta^{\prime}\right) \\
\text { subj. to } \quad c=y-r_{m} m-\mu_{h} p_{h} h
\end{gathered}
$$

whereas a household that filed for Chapter 7 bankruptcy and had to liquidate its home (either because of having non-exempt home equity, being hit by a moving shock, or being foreclosed upon) and consumes its endowment net of rental costs:

$$
W_{7}^{\text {liquidate }}(y, a, z)=U\left(y-p_{r} \underline{h}, \underline{h}\right)+\beta \mathbb{E}_{y^{\prime}, z^{\prime} \mid z} V_{7}^{r e n t}\left(a+y^{\prime}, z^{\prime}\right)
$$

A homeowner that files for Chapter 13 bankruptcy and is not hit by the moving shock is allowed to adjust its mortgage (but not refinance) and save, but not borrow unsecured:

$$
\begin{gathered}
W_{13}^{\text {own }}(a, h, m, \phi, \omega, z)=\max _{c, m \geq m^{\prime} \geq 0, b^{\prime} \geq 0}\left\{U(c, h)+\beta \mathbb{E}_{p_{h}^{\prime}, \omega^{\prime}, y^{\prime}, z^{\prime}, \theta^{\prime} \mid \omega, z} V_{13}^{\text {own }}\left(b^{\prime}, h, m^{\prime}, \phi, p_{h}^{\prime}, \omega^{\prime}, y^{\prime}, z^{\prime}, \theta^{\prime}\right)\right\} \\
\text { subj. to } \quad c+m\left(1+r_{m}\right)-m^{\prime}+b^{\prime} q_{b}\left(b^{\prime}, h, m^{\prime}, \omega, z, 13\right)-\mu_{h} p_{h} h \leq a
\end{gathered}
$$

A homeowner that filed for Chapter 13 bankruptcy and is hit by the moving shock solves the following:

$$
\begin{gathered}
W_{13}^{r e n t}(a, \phi, z)=\max _{c, b^{\prime} \geq 0}\left\{U(c, \underline{h})+\beta \mathbb{E}_{y^{\prime}, z^{\prime} \mid z} V_{13}^{r e n t}\left(b^{\prime}, \phi, y^{\prime}, z^{\prime}\right)\right\} \\
\text { subj. to } \quad c+p_{r} \underline{h}+b^{\prime} q_{b}\left(b^{\prime}, h, m^{\prime}, \omega, z, 13\right) \leq a
\end{gathered}
$$

and a homeowner that defaults on its mortgage but does not file for bankruptcy solves:

$$
\begin{aligned}
& W_{F}^{r e n t}(a, z)=\max _{c, b^{\prime} \geq 0}\left\{U(\lambda c, \underline{h})+\beta \mathbb{E}_{y^{\prime}, z^{\prime} \mid z} V_{F}^{r e n t}\left(b^{\prime}, y^{\prime}, z^{\prime}\right)\right\} \\
& \text { subj. to } \quad c+p_{r} \underline{h}+b^{\prime} q_{b}\left(b^{\prime}, z, F\right) \leq a
\end{aligned}
$$

Now, we turn to the problem of a renter who begins the period with a good credit history, who can choose to buy a home, stay a renter, or file for Chapter 7 or Chapter 13 bankruptcy, and has lifetime utility given by:

$$
V_{G}^{r e n t}(b, y, z)=\left\{W_{G}^{\text {buy }}(b+y, z), W_{G}^{\text {rent }}(b+y, z), W_{7}^{\text {liquidate }}(y, 0, z), W_{13}^{\text {rent }}(y, 0, z)\right\}
$$


Note, the value function $W_{7}^{\text {liquidate }}$ evaluated a 0 home equity is equivalent to a renter who files for bankruptcy.

A homeowner that starts the period with a previous Chapter 7 bankruptcy as its credit history chooses whether to keep or sell its house, or whether to default on its mortgage. After the discrete choice, the household learns whether its credit history stochastically reverts to $G$ or stays 7 . If the household sold its house, it can then choose whether to buy a new home, or stay as a renter. Note, that if a household with a bankruptcy files for foreclosure, the credit history stays as 7 , the assumption being that the bankruptcy is a worse credit event. Further, a household is only allowed to file for Chapter 7 bankruptcy on a deficiency judgment if not doing so would result in non-positive consumption.

$V_{7}^{\text {own }}\left(b, h, m, p_{h}, \omega, y, z, \theta=0\right)=$

$\max \left\{\begin{array}{cl}\text { No def., keep house: } & \alpha_{7} W_{G}^{\text {own }}(b+y, h, m, \omega, z)+ \\ & \left(1-\alpha_{7}\right) W_{7}^{\text {own }}(b+y, h, m, \omega, z) \\ \text { No def., sell house: } & \alpha_{7} \max \left\{W_{G}^{\text {buy }}(\eta+b+y, z), W_{G}^{\text {rent }}(\eta+b+y, z)\right\}+ \\ & \left(1-\alpha_{7}\right) \max \left\{W_{7}^{\text {buy }}(\eta+b+y, z), W_{7}^{\text {rent }}(\eta+b+y, z)\right\} \\ & \mathbb{E}_{\mathcal{J}}\left[(1-\mathcal{J}) W_{7}^{\text {rent }}\left(b_{F}+y, z\right)+\right. \\ & \left.\mathcal{J}\left(\mathbf{1}_{b_{F}>0} W_{7}^{\text {rent }}\left(b_{F}+y, z\right)+\left(1-\mathbf{1}_{b_{F}>0}\right) W_{7}^{\text {liquidate }}(y, 0, z)\right)\right]\end{array}\right\}$

where the value of not defaulting on the mortgage and keeping the house conditional on not transitioning to good credit is:

$$
\begin{gathered}
W_{7}^{\text {own }}(a, h, m, \omega, z)=\max _{c, m \geq m^{\prime} \geq 0, b^{\prime} \geq 0}\left\{U(\lambda c, h)+\beta \mathbb{E}_{p_{h}^{\prime}, \omega^{\prime}, y^{\prime}, z^{\prime}, \theta^{\prime} \mid \omega, z} V_{G}^{\text {own }}\left(b^{\prime}, h, m^{\prime}, p_{h}^{\prime}, \omega^{\prime}, y^{\prime}, z^{\prime}, \theta^{\prime}\right)\right\} \\
\text { subj. to } \quad c+m\left(1+r_{m}\right)-m^{\prime}+b^{\prime} q_{b}\left(b^{\prime}, h, m^{\prime}, \omega, z, 7\right)--\mu_{h} p_{h} h \leq a
\end{gathered}
$$

and the value of not defaulting on the mortgage, selling the house and buying a new one conditional on not transitioning to good credit is:

$$
\begin{aligned}
& W_{7}^{\text {buy }}(a, z)=\max _{c, h^{\prime} \in \mathcal{H}, b^{\prime} \geq 0}\left\{U\left(\lambda c, h^{\prime}\right)+\beta \mathbb{E}_{p_{h}^{\prime}, \omega^{\prime}, y^{\prime}, z^{\prime}, \theta^{\prime} \mid \omega, z} V_{7}^{\text {own }}\left(b^{\prime}, h^{\prime}, 0, p_{h}^{\prime}, \omega^{\prime}, y^{\prime}, z^{\prime}, \theta^{\prime}\right)\right\} \\
& \text { subj. to } \quad c+p_{h} h^{\prime}+b^{\prime} q_{b}\left(b^{\prime}, h, 0, \omega, z, 7\right)-\mu_{h} p_{h} h^{\prime} \leq a \\
& \text { where: } p_{h}=1, \omega=0
\end{aligned}
$$

and the value of not defaulting on the mortgage, selling the house and becoming a renter conditional on not transitioning to good credit is:

$$
\begin{aligned}
& W_{7}^{r e n t}(a, z)=\max _{c, b^{\prime} \geq 0}\left\{U(\lambda c, \underline{h})+\beta \mathbb{E}_{y^{\prime}, z^{\prime} \mid z} V_{7}^{r e n t}\left(b^{\prime}, y^{\prime}, z^{\prime}\right)\right\} \\
& \text { subj. to } \quad c+p_{r} \underline{h}+b^{\prime} q_{b}\left(b^{\prime}, z, 7\right) \leq a
\end{aligned}
$$


A homeowner that starts the period with a previous Chapter 7 bankruptcy as its credit history that is hit by the moving shock chooses whether to sell its house or whether to default on its mortgage. After the discrete choice, the household learns whether its credit history stochastically reverts to $G$ or stays 7 . If the household sold its house, it can then choose whether to buy a new home, or stay as a renter. Note, that if a household with a bankruptcy files for foreclosure, the credit history stays as 7, the assumption being that the bankruptcy is a worse credit event. Further, a household is only allowed to file for Chapter 7 bankruptcy on a deficiency judgment if not doing so would result in non-positive consumption.

$$
\begin{aligned}
& V_{7}^{\text {own }}\left(b, h, m, p_{h}, \omega, y, z, \theta=1\right)= \\
& \max \left\{\begin{aligned}
& \text { No def., sell house: } \alpha_{7} \max \left\{W_{G}^{\text {buy }}(\eta+b+y, z), W_{G}^{\text {rent }}(\eta+b+y, z)\right\}+ \\
& \text { Mort. def }\left(1-\alpha_{7}\right) \max \left\{W_{7}^{\text {buy }}(\eta+b+y, z), W_{7}^{\text {rent }}(\eta+b+y, z)\right\} \\
& \mathbb{E}_{\mathcal{J}}\left[(1-\mathcal{J}) W_{7}^{\text {rent }}\left(b_{F}, z\right)+\right. \\
&\left.\mathcal{J}\left(\mathbf{1}_{b_{F}>0} W_{7}^{\text {rent }}\left(b_{F}, z\right)+\left(1-\mathbf{1}_{b_{F}>0}\right) W_{7}^{\text {liquidate }}(y, 0, z)\right)\right]
\end{aligned}\right\}
\end{aligned}
$$

where $\eta=p_{h} h-\left(1+r_{m}\right) m$ and $b_{F}$ is defined as in the main text.

A renter that starts the period with a previous Chapter 7 bankruptcy as its credit history learns whether it receives a good credit history, then decides whether to buy a home or stay as a renter:

$$
V_{7}^{\text {rent }}(b, y, z)=\left\{\begin{array}{c}
\alpha_{7} \max \left\{W_{G}^{\text {buy }}(b+y, z)+W_{G}^{\text {rent }}(b+y, z)\right\}+ \\
\left(1-\alpha_{7}\right) \max \left\{W_{7}^{\text {buy }}(b+y, z), W_{7}^{\text {rent }}(b+y, z)\right\}
\end{array}\right\}
$$

A homeowner that starts the period with a previous Chapter 13 bankruptcy as its credit history that is not hit by the moving shock chooses whether to keep or sell its house, or whether to default on its mortgage. After the discrete choice, the household learns whether its credit history stochastically reverts to $G$ or stays 13 . If the household sold its house, it can then choose whether to buy a new home, or stay as a renter. Note, that if a household with a bankruptcy files for foreclosure, the credit history stays as 7 , the assumption being that the bankruptcy is a worse credit event. Further, a household is only allowed to file for Chapter 7 bankruptcy on a deficiency judgment if not doing so would result in non-positive consumption.

$$
\begin{aligned}
& V_{13}^{\text {own }}\left(b, h, m, \phi, p_{h}, \omega, y, z, \theta=0\right)= \\
& \max \begin{cases}\text { No def., keep house: } & \alpha_{13} W_{G}^{\text {own }}(b+y, h, m, \omega, z)+ \\
& \left(1-\alpha_{13}\right) W_{13}^{\text {own }}(b+(1-\phi) y, h, m, \phi, \omega, z) \\
\text { No def., sell house: } & \alpha_{13} \max \left\{W_{G}^{\text {buy }}(\eta+b+y, z), W_{G}^{\text {rent }}(\eta+b+y, z)\right\}+ \\
& \left(1-\alpha_{13}\right) \max \left\{W_{13}^{\text {buy }}(\eta+b+(1-\phi) y, \phi, z), W_{13}^{\text {rent }}(\eta+b+(1-\phi) y, \phi, z)\right\} \\
\text { Mort. def } & \mathbb{E}_{\mathcal{J}}\left[(1-\mathcal{J}) W_{13}^{\text {rent }}\left(b_{F}+(1-\phi) y, \phi, z\right)+\right. \\
\left.\mathcal{J}\left(\mathbf{1}_{b_{F}>0} W_{13}^{\text {rent }}\left(b_{F}+(1-\phi) y, \phi, z\right)+\left(1-\mathbf{1}_{b_{F}>0}\right) W_{7}^{\text {liquidate }}(y, 0, z)\right)\right]\end{cases}
\end{aligned}
$$

where the value of not defaulting on the mortgage, selling the house and buying a new one conditional on not transitioning to good credit is: 


$$
\begin{aligned}
& W_{13}^{\text {buy }}(a, \phi, z)=\max _{c, h^{\prime} \in \mathcal{H}, b^{\prime} \geq 0}\left\{U\left(\lambda c, h^{\prime}\right)+\beta \mathbb{E}_{p_{h}^{\prime}, \omega^{\prime}, y^{\prime}, z^{\prime}, \theta^{\prime} \mid \omega, z} V_{13}^{\text {own }}\left(b^{\prime}, h^{\prime}, 0, p_{h}^{\prime}, \omega^{\prime}, y^{\prime}, z^{\prime}, \theta^{\prime}\right)\right\} \\
& \text { subj. to } \quad c+p_{h} h^{\prime}+b^{\prime} q_{b}\left(b^{\prime}, h, 0, \omega, z, 7\right)-\mu_{h} p_{h} h^{\prime} \leq a \\
& \text { where: } p_{h}=1, \omega=0
\end{aligned}
$$

A homeowner that starts the period with a previous Chapter 13 bankruptcy as its credit history that is hit by the moving shock chooses whether to sell its house, or whether to default on its mortgage:

$V_{13}^{\text {own }}\left(b, h, m, \phi, p_{h}, \omega, y, z, \theta=1\right)=$

$$
\max \left\{\begin{aligned}
\text { No def., sell house: } & \alpha_{13} \max \left\{W_{G}^{\text {buy }}(\eta+b+y, z), W_{G}^{\text {rent }}(\eta+b+y, z)\right\}+ \\
& \left(1-\alpha_{13}\right) \max \left\{W_{13}^{\text {buy }}(\eta+b+(1-\phi) y, \phi, z), W_{13}^{\text {rent }}(\eta+b+(1-\phi) y, \phi, z)\right\} \\
& \mathbb{E}_{\mathcal{J}}\left[(1-\mathcal{J}) W_{13}^{\text {rent }}\left(b_{F}+(1-\phi) y, \phi, z\right)+\right. \\
& \left.\mathcal{J}\left(\mathbf{1}_{b_{F}>0} W_{13}^{\text {rent }}\left(b_{F}+(1-\phi) y, \phi, z\right)+\left(1-\mathbf{1}_{b_{F}>0}\right) W_{7}^{\text {liquidate }}(y, 0, z)\right)\right]
\end{aligned}\right.
$$

A renter that starts the period with a previous Chapter 13 bankruptcy as its credit history learns whether it receives a good credit history, then decides whether to buy a home or stay as a renter:

$$
V_{13}^{r e n t}(b, y, \phi, z)=\left\{\begin{array}{l}
\alpha_{13} \max \left\{W_{G}^{\text {buy }}(b+y, z)+W_{G}^{\text {rent }}(b+y, z)\right\}+ \\
\left(1-\alpha_{13}\right) \max \left\{W_{13}^{\text {buy }}(b+(1-\phi) y, \phi, z), W_{13}^{\text {rent }}(b+(1-\phi) y, \phi, z)\right\}
\end{array}\right\}
$$

A homeowner that starts the period with a previous foreclosure as its credit history that is not hit by the moving shock chooses whether to keep or sell its house. After the discrete choice, the household learns whether its credit history stochastically reverts to $G$ or stays $F$. If the household sold its house, it can then choose whether to buy a new home, or stay as a renter. Note that a household with the foreclosure credit history cannot have a mortgage.

$$
\begin{aligned}
& V_{F}^{\text {own }}\left(b, h, p_{h}, \omega, y, z, \theta=0\right)= \\
& \max \left\{\begin{array}{ll}
\text { Keep house: } & \alpha_{F} W_{G}^{\text {own }}(b+y, h, 0, \omega, z)+ \\
& \left(1-\alpha_{F}\right) W_{F}^{\text {own }}(b+(1-\phi) y, h, \omega, z) \\
\text { Sell house: } & \alpha_{F} \max \left\{W_{G}^{\text {buy }}(\eta+b+y, z), W_{G}^{\text {rent }}(\eta+b+y, z)\right\}+ \\
& \left(1-\alpha_{F}\right) \max \left\{W_{F}^{\text {buy }}(\eta+b+y, z), W_{F}^{\text {rent }}(\eta+b+y, z)\right\}
\end{array}\right\}
\end{aligned}
$$

where

$$
\begin{gathered}
W_{F}^{\text {own }}(a, h, \omega, z)=\max _{c, b^{\prime} \geq 0}\left\{U(\lambda c, h)+\beta \mathbb{E}_{p_{h}^{\prime}, \omega^{\prime}, y^{\prime}, z^{\prime}, \theta^{\prime} \mid \omega, z} V_{F}^{\text {own }}\left(b^{\prime}, h, p_{h}^{\prime}, \omega^{\prime}, y^{\prime}, z^{\prime}, \theta^{\prime}\right)\right\} \\
\text { subj. to } \quad c+{ }^{\prime} q_{b}\left(b^{\prime}, h, m^{\prime}, \omega, z, 7\right)-\mu_{h} p_{h} h \leq a
\end{gathered}
$$


and a household with the foreclosure history that buys a house solves:

$$
\begin{aligned}
& W_{F}^{\text {buy }}(a, z)=\max _{c, h^{\prime} \in \mathcal{H}, b^{\prime} \geq 0}\left\{U\left(\lambda c, h^{\prime}\right)+\beta \mathbb{E}_{p_{h}^{\prime}, \omega^{\prime}, y^{\prime}, z^{\prime}, \theta^{\prime} \mid \omega, z} V_{F}^{\text {own }}\left(b^{\prime}, h^{\prime}, 0, p_{h}^{\prime}, \omega^{\prime}, y^{\prime}, z^{\prime}, \theta^{\prime}\right)\right\} \\
& \text { subj. to } c+p_{h} h^{\prime}+b^{\prime} q_{b}\left(b^{\prime}, h, 0, \omega, z, F\right)-\mu_{h} p_{h} h^{\prime} \leq a \\
& \text { where: } p_{h}=1, \omega=0
\end{aligned}
$$

A renter that starts the period with a previous foreclosure as its credit history learns whether it receives a good credit history, then decides whether to buy a home or stay as a renter:

$$
V_{7}^{\text {rent }}(b, y, z)=\left\{\begin{array}{c}
\alpha_{F} \max \left\{W_{G}^{\text {buy }}(b+y, z)+W_{G}^{\text {rent }}(b+y, z)\right\}+ \\
\left(1-\alpha_{F}\right) \max \left\{W_{F}^{\text {buy }}(b+y, z), W_{F}^{\text {rent }}(b+y, z)\right\}
\end{array}\right\}
$$




\section{Full Specification of the Intermediary's Problem}

Here I restate the problem of an intermediary who chooses whether to originate a mortgage.

$$
\begin{gathered}
q_{m}\left(b^{\prime}, h^{\prime}, m^{\prime}, z, \omega, G\right) m^{\prime} \geq \frac{1}{1+r_{b}+r_{m}} \times \mathbb{E}_{p_{h}^{\prime}, \omega^{\prime}, y^{\prime}, z^{\prime}, \theta^{\prime} \mid z, \omega} \\
\left\{\begin{array}{c}
\left(S_{G}^{*}\left(X^{\prime}\right)+R^{*}\left(X^{\prime}\right)\right)\left(1+r_{m}\right) m^{\prime}+ \\
P_{G}^{*}\left(X^{\prime}\right)\left(\left(1+r_{m}\right) m^{\prime}-m^{\prime \prime}+m^{\prime \prime} q_{m}\left(b^{\prime \prime}, h^{\prime}, m^{\prime \prime}, z^{\prime}, \omega^{\prime}, G\right)\right)+ \\
\left(1-\mathbf{1}_{\eta \leq \chi}\left(1-\theta^{\prime}\right)\right)\left(1+r_{m}\right) m^{\prime}+ \\
\left(1-f_{G}^{*}\left(X^{\prime}\right)\right) B 7^{*}\left(X^{\prime}\right)\left[\begin{array}{c}
(26) \\
\left(1-\theta^{\prime}\right) \mathbf{1}_{\eta \leq \chi}\left(r_{m} m^{\prime}+m^{\prime} q_{m}\left(0, h^{\prime}, m^{\prime}, z^{\prime}, \omega^{\prime}, 7\right)\right)
\end{array}\right]+ \\
\theta^{\prime}\left(1+r_{m}\right) m^{\prime}+ \\
\left(1-f_{G}^{*}\left(X^{\prime}\right)\right) B 13^{*}\left(X^{\prime}\right)\left[\begin{array}{c}
\left(1-\theta^{\prime}\right)\left(\left(1+r_{m}\right) m^{\prime}-m^{\prime \prime}+m^{\prime \prime} q_{m}\left(b^{\prime \prime}, h^{\prime}, m^{\prime \prime}, \phi, z^{\prime}, \omega^{\prime}, 13\right)\right)
\end{array}\right]+ \\
f_{G}^{*}\left(X^{\prime}\right)\left[\begin{array}{c}
\psi\left(h^{\prime}\right)\left(\left(1-B^{*}\right)\left(1+r_{m}\right) m^{\prime}+B^{*}\left(\gamma p_{h}^{\prime} h^{\prime}+\max \left(b^{\prime}, 0\right)\right)\right)+ \\
\left(1-\psi\left(h^{\prime}\right)\right)\left(\gamma p_{h}^{\prime} h^{\prime}\right)
\end{array}\right]
\end{array}\right\}
\end{gathered}
$$

Even though households with bad credit histories can't originate new mortgages, the bank needs forecast the expected returns to existing mortgages when households file for bankruptcy. The price of a mortgage for a household that filed chapter 7 bankruptcy is given by:

$$
\begin{aligned}
& q_{m}\left(b^{\prime}, h^{\prime}, m^{\prime}, z, \omega, 7\right) m^{\prime}=\frac{1}{1+r_{b}+r_{m}} \times \mathbb{E}_{p_{h}^{\prime}, \omega^{\prime}, y^{\prime}, z^{\prime}, \theta^{\prime} \mid z, \omega} \\
& \left\{\begin{array}{c}
\left(S_{7}^{*}\left(X^{\prime}\right)\right)\left(1+r_{m}\right) m^{\prime}+ \\
P_{7}^{*}\left(X^{\prime}\right)\left[\begin{array}{c}
\alpha_{7}\left(\left(1+r_{m}\right) m^{\prime}-m_{G}^{\prime \prime}+m_{G}^{\prime \prime} q_{m}\left(b_{G}^{\prime \prime}, h^{\prime}, m_{G}^{\prime \prime}, z^{\prime}, \omega^{\prime}, G\right)\right)+ \\
\left.\left(1-\alpha_{7}\right)\left(\left(1+r_{m}\right) m^{\prime}-m_{7}^{\prime \prime}+m_{7}^{\prime \prime} q_{m}\left(b_{7}^{\prime \prime}, h^{\prime}, m_{7}^{\prime \prime}, z^{\prime}, \omega^{\prime}, 7\right)\right)\right)
\end{array}\right]+ \\
f_{7}^{*}\left(X^{\prime}\right)\left[\begin{array}{c}
\psi\left(h^{\prime}\right)\left(\mathbf{1}_{b_{F}^{\prime}+y^{\prime}>0}\left(1+r_{m}\right) m^{\prime}+\left(1-\mathbf{1}_{b_{F}^{\prime}+y^{\prime}>0}\right)\left(\gamma p_{h}^{\prime} h^{\prime}+\max \left(b^{\prime}, 0\right)\right)+\right. \\
+\left(1-\psi\left(h^{\prime}\right)\right)\left(\gamma p_{h}^{\prime} h^{\prime}\right)
\end{array}\right]
\end{array}\right\}
\end{aligned}
$$

And similarly for Chapter 13:

$$
\begin{aligned}
& q_{m}\left(b^{\prime}, h^{\prime}, m^{\prime}, z, \omega, 13\right) m^{\prime}=\frac{1}{1+r_{b}+r_{m}} \times \mathbb{E}_{p_{h}^{\prime}, \omega^{\prime}, y^{\prime}, z^{\prime}, \theta^{\prime} \mid z, \omega} \\
& \left\{\begin{array}{c}
\left(S_{13}^{*}\left(X^{\prime}\right)\right)\left(1+r_{m}\right) m^{\prime}+ \\
P_{13}^{*}\left(X^{\prime}\right)\left[\begin{array}{c}
\alpha_{13}\left(\left(1+r_{m}\right) m^{\prime}-m_{G}^{\prime \prime}+m_{G}^{\prime \prime} q_{m}\left(b_{G}^{\prime \prime}, h^{\prime}, m_{G}^{\prime \prime}, z^{\prime}, \omega^{\prime}, G\right)\right)+ \\
\left.\left(1-\alpha_{13}\right)\left(\left(1+r_{m}\right) m^{\prime}-m_{13}^{\prime \prime}+m_{13}^{\prime \prime} q_{m}\left(b_{13}^{\prime \prime}, h^{\prime}, m_{13}^{\prime \prime}, z^{\prime}, \omega^{\prime}, 13\right)\right)\right)
\end{array}\right]+ \\
f_{13}^{*}\left(X^{\prime}\right)\left[\begin{array}{c}
\psi\left(h^{\prime}\right)\left(\mathbf{1}_{b_{F}^{\prime}+y^{\prime}>0}\left(1+r_{m}\right) m^{\prime}+\left(1-\mathbf{1}_{b_{F}^{\prime}+y^{\prime}>0}\right)\left(\gamma p_{h}^{\prime} h^{\prime}+\max \left(b^{\prime}, 0\right)\right)+\right. \\
+\left(1-\psi\left(h^{\prime}\right)\right)\left(\gamma p_{h}^{\prime} h^{\prime}\right)
\end{array}\right]
\end{array}\right\}
\end{aligned}
$$

The pricing equations are similar to that of a household with good credit, except households with bad credit histories can't refinance, and can only file for bankruptcy if they receive a deficiency judgment which would result in non-positive consumption (but households retain the option to default on the mortgage). The equations also reflect the fact that the credit history evolves after the decision to default on the mortgage. Thus, this system of three equations determine the price for originating a new mortgage. 
Here I restate the problem of an intermediary issuing unsecured debt. When households are saving in bonds, $b^{\prime} \geq 0, q_{b}$ represents the price of buying a bond that pays $b^{\prime}$ units of consumption good tomorrow. There is no default risk on savings and thus for a homeowner:

$$
q_{b}\left(b^{\prime}, h^{\prime}, m^{\prime}, \omega, z, \mathcal{C}\right) \leq \frac{1}{1+r_{b}}
$$

and for a renter

$$
q_{b}\left(b^{\prime}, z, \mathcal{C}\right) \leq \frac{1}{1+r_{b}}
$$

which from the zero profit condition immediately implies that the price only depends on the risk-free rate, $q_{b}=\frac{1}{1+r_{b}}$ when $b^{\prime} \geq 0$ for both homeowners and renters.

When households have a bad credit history, they cannot take on unsecured debt, so $q_{b}=0$ when the credit history is $F, 7$, or 13 . For a renter with a good credit history, the price of a bond with negative face value $b^{\prime}$ depends on the household's probability of filing for bankruptcy. The bank receives nothing if the household files for Chapter 7 bankruptcy, and will receive partial repayment if the household files for Chapter 13, otherwise it receives the face value of the debt. The condition for the bank issuing unsecured debt of size $b^{\prime}$ to a renter is therefore:

$$
-b^{\prime} q_{b}\left(b^{\prime}, z\right) \geq \frac{1}{1+r_{b}+r_{u}} \times \mathbb{E}_{y^{\prime}, z^{\prime} \mid z}\left\{-b^{\prime}\left(1-B 7^{*}\left(X^{\prime}\right)-B 13^{*}\left(X^{\prime}\right)\right)+B 13^{*}\left(X^{\prime}\right) \phi \bar{y}\right\}
$$

For a homeowner, the problem of the bank also depends on the home equity of a household and its non-exempt assets, since they can be seized if a household files for Chapter 7 and places restrictions on whether the household can file for Chapter 13. If a household declares bankruptcy and has home equity in excess of the homestead exemption $\chi$ the bank can recover a fraction of it. Let $\xi^{\prime}$ denote the non-exempt portion of a household's home equity, namely $\xi^{\prime}=\max \left\{p_{h}^{\prime} h^{\prime}-\left(1+r_{m}\right) m^{\prime}-\chi, 0\right\}$. Through the bankruptcy technology, the bank can recover $\max \left\{-b^{\prime}, \zeta \xi^{\prime}\right\}$ from a household that declares bankruptcy, where $\zeta \leq 1$ represents the bankruptcy recovery technology. If the household files for Chapter 13, the bank recovers $\phi \bar{y}$. Households can only file for Chapter 13 bankruptcy if $\phi \bar{y} \geq \zeta \xi^{\prime}$. The condition for the bank issuing unsecured debt of size $b^{\prime}$ to a household with characteristics $X^{\prime}$ is:

$$
\begin{aligned}
-b^{\prime} q_{b}\left(b^{\prime}, h^{\prime}, m^{\prime}, p_{h}^{\prime}, \omega, z\right) & \geq \frac{1}{1+r_{b}+r_{u}} \times \\
\mathbb{E}_{\mathcal{J}, p_{h}^{\prime}, \omega^{\prime}, y^{\prime}, z^{\prime}, \theta^{\prime} \mid z, \omega} & \left\{\left[-b^{\prime}\left(1-B 7_{\mathcal{J}}^{*}\left(X^{\prime}\right)-B 13_{\mathcal{J}}^{*}\left(X^{\prime}\right)\right)+B 7_{\mathcal{J}}^{*}\left(X^{\prime}\right) \zeta \xi^{\prime}+B 13_{\mathcal{J}}^{*}\left(X^{\prime}\right) \phi \bar{y}\right]\right\}
\end{aligned}
$$

where the $B^{*}$ indexed by $\mathcal{J}$ represents the bankruptcy choice conditional on any foreclosure and deficiency judgment realization.

\section{Equilibrium Definition}

Let $\mu$ denote the cross sectional distribution of households over the credit history, cash at hand, income and home ownership status, house size, house price, mortgage size and income penalty. I focus on a stationary recursive equilibrium. 
Definition Given $(\psi, \chi)$ and $r_{b}$, a Stationary Recursive Competitive Equilibrium comprises:

- Value functions for the households,

$$
\begin{aligned}
& \left\{V^{\text {own }}: \mathcal{C} \times \mathbb{R}^{4} \times \Omega \times Y \times Z \times\{0,1\} \rightarrow \mathbb{R}\right\},\left\{V^{\text {rent }}: \mathcal{C} \times \mathbb{R} \times Y \times Z \rightarrow \mathbb{R}\right\}, \\
& \left\{W^{\text {own }}: \mathcal{C} \times \mathbb{R}^{3} \times \Omega \times Z \rightarrow \mathbb{R}\right\},\left\{W^{\text {rent }}: \mathcal{C} \times \mathbb{R} \times Z \rightarrow \mathbb{R}\right\},\left\{W^{\text {buy }}: \mathcal{C} \times \mathbb{R} \times Z \rightarrow \mathbb{R}\right\}, \\
& \left\{W_{7}^{\text {keep }}: \mathbb{R}^{2} \times \Omega \times Y \times Z \rightarrow \mathbb{R}\right\},\left\{W_{7}^{\text {liquidate }}: \mathbb{R} \times Y \times Z \rightarrow \mathbb{R}\right\}
\end{aligned}
$$

- Default decision rules and policy functions for the households:

$\left\{f^{*}: \mathcal{C} \times \mathbb{R}^{4} \times \Omega \times Y \times Z \times\{0,1\} \rightarrow\{0,1\}\right\},\left\{B^{*}: \mathbb{R}^{4} \times \Omega \times Y \times Z \times\{0,1\}^{2} \rightarrow\{0,1\}\right\}$ $\left\{S^{*}: \mathcal{C} \times \mathbb{R}^{4} \times \Omega \times Y \times Z \times\{0,1\}^{2} \rightarrow\{0,1\}\right\},\left\{R_{G}^{*}: \mathbb{R}^{4} \times \Omega \times Y \times Z \times\{0,1\}^{2} \rightarrow\{0,1\}\right\}$ and $\left\{c, b^{\prime}, m^{\prime}, h^{\prime}\right\}$ (whose domains are associated with the $W$ value functions

- Pricing functions $\left\{q_{m}: \mathcal{C} \times \mathcal{H} \times \mathbb{R}^{3} \times \Omega \times Z \rightarrow \mathbb{R}_{+}\right\}$and $\left\{q_{b}: \mathcal{H} \times \mathbb{R}^{3} \times \Omega \times Z \rightarrow \mathbb{R}_{+}\right\}$

- An invariant distribution: $\left\{\mu^{*}\right\}$

such that:

1. Households Maximize: Given prices and the pricing functions, the value functions solve the household problem, and $c, s, b^{\prime}, h^{\prime}, m^{\prime}$ are the associated policy functions, and $B 7^{*}, B 13^{*}, f^{*}$ are the associated default rules.

2. Zero Profit Mortgages: Given $f^{*}, B^{*}, q_{m}$ solves (26 28) with equality for any contract traded in equilibrium

3. Zero Profit Unsecured Debt: Given $f^{*}, f^{*}, B^{*}, q_{b}$ solves (29) with equality for any contract traded in equilibrium

4. Zero Profit Bonds: $q_{b}=\frac{1}{1+r_{b}}$ when $b^{\prime} \geq 0$.

5. Invariant Distribution: The distribution $\mu^{*}$ is invariant with respect to the Markov process induced by the exogenous Markov processes $\omega, z$ and the policy functions $m^{\prime}$, $h^{\prime}, b^{\prime}, B 7^{*}, B 13^{*}, f^{*}, S^{*}, R^{*}, P^{*}$

\section{Additional Results and Proofs Related to the House- hold Problem}

Assumption $1 U(c, s): \mathbb{R}_{+}^{2} \rightarrow \mathbb{R}$ is strictly increasing, concave and differentiable. Further, it is bounded above by $\bar{U}$, and given $p_{r}>0$,

$$
U\left(\underline{y}^{z} / \lambda-p_{r} \underline{h}, \underline{h}\right)-U(0, \underline{h})>\frac{\beta}{1-\beta}\left(\bar{U}-u\left(\underline{y}^{z} / \lambda-p_{r} \underline{h}, \underline{h}\right) \quad \forall z\right.
$$


Let $M=\left\{m_{1}, m_{2}, \cdots, m_{n_{m}}\right\} \subset \mathbb{R}_{+}$be the mortgage choice set, $B=\left\{b_{1}, b_{2}, \cdots, b_{n_{b}}\right\} \subset \mathbb{R}$ be the bond/unsecured choice set and $B_{+}=B \cap \mathbb{R}_{+}$be positive bond choices, $\mathcal{H} \subset \mathbb{R}_{+}$be the housing choice set, $C \subset \mathbb{R}_{+}$be the consumption expenditure choice set. The continuous state variable, cash-at-hand, $a \in A \subset \mathbb{R}_{+}$. Let $Z$ and $Y$ be the set of possible realizations for the persistent income shock and income, and let $\Omega$ and $\mathcal{P}$ by the set of possible realizations for the persistent house price shock and house price. The possible credit histories are $\mathcal{C}=$ $\{G, F, 7,13\}$. For the household problem, I take the pricing functions $q_{b}^{\text {rent }}: B \times Z \times \rightarrow \mathbb{R}_{+}$, $q_{b}^{\text {own }}: B \times H \times M \times Z \times \Omega \rightarrow \mathbb{R}_{+}$and $q_{m}: B \times H \times M \times Z \times \Omega \times \mathcal{H} \rightarrow \mathbb{R}_{+}$as given. To economize on notation, I will typically not make explicit the dependence of the prices on the choice parameters.

I define the budget correspondences for households based on the above defined value functions:

$$
\begin{aligned}
\Gamma_{G}^{o w n}(a, h, m, \omega, z) & = \\
\left\{\left(c, b^{\prime}, m^{\prime}\right)\right. & \left.\in C \times B \times M: c+b^{\prime} q_{b}+\left(1+r_{m}\right) m-m^{\prime} Q_{m}+\mu_{h} p_{h} h \leq a\right\}
\end{aligned}
$$

For $i \in\{7,13\}$

$$
\begin{gathered}
\Gamma_{i}^{o w n}(a, h, m, \omega, z)= \\
\left\{\left(c, b^{\prime}, m^{\prime}\right) \in C \times B_{+} \times M: c+b^{\prime} q_{b}+\left(1+r_{m}\right) m-m^{\prime}+\mu_{h} p_{h} h \leq a ; m^{\prime} \leq m\right\} \\
\Gamma_{F}^{o w n}(a, h, \omega, z)=\left\{\left(c, b^{\prime}\right) \in C \times B_{+}: c+b^{\prime} q_{b}+\mu_{h} p_{h} h \leq a\right\} \\
\Gamma_{G}^{b u y}(a, z)=\left\{\left(c, b^{\prime}, m^{\prime}, h^{\prime}\right) \in C \times B \times M \times H: c+b^{\prime} q_{b}-m^{\prime} q_{m}+p_{h}\left(1+\mu_{h}\right) h^{\prime} \leq a ; m^{\prime} \leq h^{\prime}\right\}
\end{gathered}
$$

For $i \in\{F, 7,13\}$

$$
\begin{gathered}
\Gamma_{i}^{b u y}(a, z)=\left\{\left(c, b^{\prime}, h^{\prime}\right) \in C \times B_{+} \times H: c+b^{\prime} q_{b}+p_{h}\left(1+\mu_{h}\right) h^{\prime} \leq a\right\} \\
\Gamma_{G}^{r e n t}(a, z)=\left\{\left(c, b^{\prime}\right) \in C \times B: c+b^{\prime} q_{b}+p_{r} \underline{h} \leq a\right\}
\end{gathered}
$$

For $i \in\{F, 7,13\}$

$$
\Gamma_{i}^{r e n t}(a, z)=\left\{\left(c, b^{\prime}\right) \in C \times B_{+}: c+b^{\prime} q_{b}+p_{r} \underline{h} \leq a\right\}
$$

Denote the cardinality of the number of credit states by $N_{\mathcal{C}}$. Let $\mathcal{V}^{\text {own }}$ be the set of all continuous (in $b, h, m, \phi, y, z, \omega, p_{h}, \theta$ ), vector-valued functions $V^{\text {own }}: B \times H \times M \times \Phi \times Y \times$ $Z \times \Omega \times \Theta \times P \rightarrow \mathbb{R}^{N_{\mathcal{H}}}$ that are increasing in $b, h, y$ and decreasing in $m$ that satisfy the following:

$$
\begin{aligned}
V_{\mathcal{C}}^{\text {own }}\left(b, h, m, \phi, y, z, \omega, p_{h}, \theta\right) & \in\left[\frac{u(0 ; \underline{h})}{1-\beta}, \frac{\bar{u}}{1-\beta}\right] \\
V_{G}^{\text {own }}\left(b, h, m, \phi, y, z, \omega, p_{h}, \theta\right) & \geq V_{F, 7,13}^{\text {own }}\left(b, h, m, \phi, y, z, \omega, p_{h}, \theta\right)
\end{aligned}
$$


Lemma $1 \mathcal{V}^{\text {own }}$ is nonempty. With $\|V\|=\max _{H}\left\{\sup \left|V^{H}\right|\right\}$ as the norm, $\left(\mathcal{V}^{\text {own }},\|\cdot\|\right)$ is a complete metric space.

Proof Any constant vector-valued function that satisfies 40 is clearly continuous and satisfies the monotonicity requirements. The set of all continuous vector-valued functions coupled with the same norm $(\mathcal{C},\|\cdot\|)$ is a complete metric space, thus to prove that $(\mathcal{V},\|\cdot\|)$ is a complete metric space I need to show that $\mathcal{V}^{\text {own }} \subset \mathcal{C}$ is closed under the defined norm. Take an arbitrary sequence of functions from $\mathcal{V}^{\text {own }},\left\{V_{n}\right\}$ that is converging to a function $V^{*}$. If $V^{*}$ violates any of the conditions (40)-41) or the monotonicity properties, then there must exist some $N$, such that $V_{N}$ also violates those conditions or properties, but that contradicts the assertion that $V_{n} \in \mathcal{V} \forall n$. Therefore, $V^{*}$ must satisfy conditions (40)-(41) and the monotonicity properties. To prove the continuity of $V^{*}$, one can apply Theorem 3.1 in Stokey, Lucas and Prescott (1989), adapted to a vector-valued function.

Let $\mathcal{V}^{\text {rent }}$ be the set of all continuous (in $b, \phi, y, z$ ), vector-valued functions $V^{\text {rent }}: B \times$ $\Phi \times Y \times Z \rightarrow \mathbb{R}^{N_{\mathcal{H}}}$ that are increasing in $b, y$ that satisfy the following:

$$
\begin{aligned}
& V_{\mathcal{C}}^{\text {rent }}(b, \phi, y, z) \in\left[\frac{u(0 ; \underline{h})}{1-\beta}, \frac{\bar{u}}{1-\beta}\right] \\
& V_{G}^{\text {rent }}(b, \phi, y, z) \geq V_{F, 7,13}^{r e n t}(b, \phi, y, z)
\end{aligned}
$$

Lemma $2 \mathcal{V}^{\text {rent }}$ is nonempty. With $\|V\|=\max _{H}\left\{\sup \left|V^{H}\right|\right\}$ as the norm, $\left(\mathcal{V}^{\text {rent }},\|\cdot\|\right)$ is a complete metric space.

Proof Identical to above.

Let $\mathcal{V}=\mathcal{V}^{\text {own }} \cup \mathcal{V}^{\text {rent }}$. Therefore $(\mathcal{V},\|\cdot\|)$ is also complete metric space.

Lemma $3 \Gamma_{\mathcal{F}}^{B}$ is nonempty, monotone, compact-valued and continuous.

Lemma 4 Given $V^{\text {own }} \in \mathcal{V}, W_{7}^{\text {keep }}\left(h, m, y, \omega, z ; V^{\text {own }}\right)$ defined above exists, is continuous in $y$, increasing in $h$, decreasing in $m$ and strictly increasing in $y$.

Proof The existence and continuity of $W_{7}^{k e e p}\left(h, m, y, \omega, z ; V^{\text {own }}\right)$ are because $U$ and $V^{\text {own }}$ exist and are continuous. The strict monotonicity in $y$ comes from the strict monotonicity of $U$. The monotonicity in $h$ and $m$ comes from the monotonicity of $V^{\text {own }}$.

Lemma 5 Given $V^{\text {rent }} \in \mathcal{V}, W_{7}^{\text {liquidate }}\left(y, a, z ; V^{\text {rent }}\right)$ defined above exists, is continuous in $a, y$, increasing in $a$, and strictly increasing in $y$.

Proof The existence and continuity of are because $U$ and $V^{r e n t}$ exist and are continuous. The strict monotonicity in $y$ comes from the strict monotonicity of $U$. The monotonicity in a comes from the monotonicity of $V^{\text {rent }}$.

Lemma 6 Given $V^{\text {own }} \in \mathcal{V}, W_{i}^{\text {own }}\left(a, h, m, \omega, z ; V_{i}^{\text {own }}\right)$ defined by above exists, is continuous and increasing in a, and increasing in $h$. 
Proof The existence and continuity of $W_{i}^{\text {own }}\left(a, h, m, \omega, z ; V_{i}^{\text {own }}\right)$ are a direct consequence of the Theorem of the Maximum, since $V_{i}^{\text {own }}$ is continuous and $\Gamma_{i}^{\text {own }}$ is compact valued and continuous for $i \in\{F, 7,13\}$. The monotonicity in a comes from the the fact that $\Gamma_{i}^{o w n}$ is monotone in $a$ and the monotonicity of $V_{i}^{\text {own }}$. The monotonicity in $h$ comes from the monotonicity of $U$ and $V^{\text {own }}$.

Lemma 7 Given $V^{\text {rent }} \in \mathcal{V}, W_{i}^{\text {rent }}\left(a, z ; V_{i}^{\text {rent }}\right)$ defined by above exists, is continuous and increasing in a.

Proof The existence and continuity of $W_{i}^{\text {rent }}\left(a, z ; V_{i}^{\text {rent }}\right)$ are a direct consequence of the Theorem of the Maximum, since $V_{i}^{r e n t}$ is continuous and $\Gamma_{i}^{r e n t}$ is compact valued and continuous for $i \in\{F, 7,13\}$. The monotonicity in a comes from the the fact that $\Gamma_{i}^{r e n t}$ is monotone in $a$ and the monotonicity of $V_{i}^{r e n t}$.

Lemma 8 Given $V^{\text {own }} \in \mathcal{V}, W_{i}^{\text {buy }}\left(a, z ; V_{i}^{\text {rent }}\right)$ defined by 14. 19 and 24) exists, is continuous and increasing in a.

Proof The existence and continuity of $W_{i}^{\text {buy }}\left(a, z ; V_{i}^{\text {own }}\right)$ are a direct consequence of the Theorem of the Maximum, since $V_{i}^{\text {own }}$ is continuous and $\Gamma_{i}^{b u y}$ is compact valued and continuous for $i \in\{F, 7,13\}$. The monotonicity in a comes from the the fact that $\Gamma_{i}^{b u y}$ is monotone in $a$ and the monotonicity of $V_{i}^{\text {own }}$.

In order to show the existence of $W_{G}^{\text {own }}\left(a, h, m, \omega, z ; V_{G}^{\text {own }}\right), W_{G}^{\text {buy }}\left(a, z ; V_{G}^{\text {own }}\right)$ and $W_{G}^{\text {rent }}\left(a, z ; V_{G}^{\text {rent }}\right)$ I first need to extend their definitions, because for some values of $a$ the budget correspondence may be empty. First, I will denote by $c_{G}^{o w n}\left(a, h, m, \omega, z, x^{\prime}\right)$ the consumption of a household with $a, h, m, \omega, z$ who makes the portfolio choice $x^{\prime}$. Thus, $c_{G}^{\text {own }}\left(a, h, m, \omega, z, x^{\prime}\right) \equiv$ $a-b^{\prime} q_{b}-\mu_{h} p_{h} h+m^{\prime} Q_{m}-\left(1+r_{m}\right) m$. Similarly, I define $c_{G}^{r e n t}\left(a, z, x^{\prime}\right)$ and $c_{G}^{b u y}\left(a, z, x^{\prime}\right)$ as the consumption of a household with cash-at-hand $a$ who rents or buys respectively. Note that these consumptions can be negative. Using this notation, I can define lifetime utility from choosing portfolio $x^{\prime}$ as follows:

$$
\begin{aligned}
\Upsilon_{G}^{\text {own }}\left(a, h, m, \omega, z, x_{\text {own }}^{\prime} ; V_{G}^{\text {own }}\right) & \equiv u\left(\max \left\{c_{G}^{\text {own }}, 0\right\}\right)+\beta \mathbb{E}_{p_{h}^{\prime}, \omega^{\prime}, y^{\prime}, z^{\prime}, \theta^{\prime} \mid \omega, z} V_{G}^{\text {own }}\left(X_{\text {own }}^{\prime}\right) \\
\Upsilon_{G}^{\text {rent }}\left(a, x_{\text {rent }}^{\prime} ; V_{G}^{\text {rent }}\right) & \equiv u\left(\max \left\{c_{G}^{\text {rent }}, 0\right\}\right)+\beta \mathbb{E}_{y^{\prime}, z^{\prime} \mid z} V_{G}^{\text {rent }}\left(X_{\text {rent }}^{\prime}\right) \\
\Upsilon_{G}^{\text {buy }}\left(a, x_{\text {buy }}^{\prime} ; V_{G}^{\text {own }}\right) & \equiv u\left(\max \left\{c_{G}^{\text {buy }}, 0\right\}\right)+\beta \mathbb{E}_{p_{h}^{\prime}, \omega^{\prime}, y^{\prime}, z^{\prime}, \theta^{\prime} \mid \omega, z} V_{G}^{\text {own }}\left(X_{\text {buy }}^{\prime}\right)
\end{aligned}
$$

where $x_{\text {own }}^{\prime}=\left(b^{\prime}, m^{\prime}, h\right), X_{\text {own }}^{\prime}=\left(x_{\text {own }}^{\prime}, p_{h}^{\prime}, \omega^{\prime}, y^{\prime}, z^{\prime}, \theta^{\prime}\right), x_{\text {rent }}^{\prime}=\left(b^{\prime}\right), X_{\text {rent }}^{\prime}=\left(x_{\text {rent }}^{\prime}, y^{\prime}, z^{\prime}\right)$, $x_{\text {buy }}^{\prime}=\left(b^{\prime}, m^{\prime}, h^{\prime}\right)$ and $X_{\text {buy }}^{\prime}=\left(x_{\text {buy }}^{\prime}, p_{h}^{\prime}, \omega^{\prime}, y^{\prime}, z^{\prime}, \theta^{\prime}\right)$

Lemma $9 \Upsilon_{G}^{j}\left(a, z, x_{j}^{\prime} ; V\right)$ is continuous in a and $x_{j}^{\prime}$ for $j \in\{$ rent, buy $\}$. Further, for any $j, x^{\prime}, \Upsilon_{G}^{j}$ is increasing in $a$, and strictly increasing if $c_{G}^{j}\left(a, z, x_{j}^{\prime}\right)>0$.

Proof Note that $c_{G}^{j}\left(a, z, x_{j}^{\prime}\right)$ are continuous functions of $a$ and $x_{j}^{\prime}$ and $U$ is continuous in its first argument. Further, since $V^{\text {own,rent }} \in \mathcal{V}$ it is continuous in $x_{j}^{\prime}$ and integration preserves continuity. The monotonicity comes because of the strict monotonicity in $U$ and the fact that $c_{G}^{j}\left(a, z, x_{j}^{\prime}\right)$ is increasing in $a$ and strictly increasing in $a$ when $c_{G}^{j}\left(a, z, x_{j}^{\prime}\right)>0$ 
Lemma $10 \Upsilon_{G}^{\text {own }}\left(a, m, h, \omega, z, x_{\text {own }}^{\prime} ; V^{\text {own }}\right)$ is continuous in $a$ and $x_{\text {own }}^{\prime}$. Further, for any $x_{\text {own }}^{\prime}, \Upsilon_{G}^{\text {own }}$ is increasing in a, and strictly increasing if $c_{G}^{o w n}\left(a, m, h, \omega, z, x_{\text {own }}^{\prime}\right)>0$.

Proof Identical to above.

Thus, I redefine the extended value functions for $j \in\{$ rent, buy $\}$ as:

$$
W_{G}^{j}(a, z ; V)=\max _{x_{j}^{\prime} \in \bar{X}_{j}(a, z)} \Upsilon_{G}^{j}\left(a, z, x_{j}^{\prime} ; V^{\text {own,rent }}\right)
$$

and for $W_{G}^{o w n}$ as:

$$
W_{G}^{\text {own }}(a, m, h, \omega, z ; V)=\max _{x_{\text {own }}^{\prime} \in \bar{X}_{\text {own }}(a, m, h, \omega, z)} \Upsilon_{G}^{\text {own }}\left(a, m, h, \omega, z, x_{j}^{\prime} ; V^{\text {own }}\right)
$$

where $\bar{X}_{\text {buy }}(a, z)=\left\{\left(b^{\prime}, h^{\prime}, m^{\prime}\right) \in B \times H \times M: b^{\prime} q_{b}+h p_{h}-m^{\prime} q_{m} \leq a\right\} \cup \mathbf{0}, \bar{X}_{\text {rent }}(a, z)=$ $\left\{\left(b^{\prime}\right) \in B: b^{\prime} q_{b} \leq a\right\} \cup \mathbf{0}$ and $\bar{X}_{\text {own }}(a, m, h, \omega, z)=\left\{\left(b^{\prime}, m\right) \in B \times M: b^{\prime} q_{b}-m^{\prime} q_{m} \leq a\right\} \cup \mathbf{0}$ are taken to be the budget correspondences (without $c$ ).

Lemma $11 W_{G}^{j}(a, z ; V), j \in\{$ rent, buy $\}$ and $W_{G}^{\text {own }}(a, m, h, \omega, z ; V)$ exist, are continuous in their first argument and increasing in their first argument.

Proof Immediate from the Theorem of the Maximum and the monotonicity of $\Upsilon_{G}^{j}$.

Lemma 12 A bad credit history lowers lifetime utility $W_{F, 7,13} \leq W_{G}$

Proof Since $V^{j} \in \mathcal{V}$ for $j \in\{$ rent,own $\}, \alpha V_{C}^{j}+(1-\alpha) V_{G}^{j} \leq V_{G}^{j}$ for $C \in\{F, 7,13\}$. From the definition of $c\left(a, z, x^{\prime}\right), \max \left\{c_{C}\left(a, z, x^{\prime}\right), 0\right\} \leq \max \left\{c_{G}\left(a, z, x^{\prime}\right), 0\right\}$ for all $C \in\{F, 7,13\}$. Thus, from the strict monotonicity of $U, \Upsilon_{C}^{\text {own }} \leq \Upsilon_{G}^{\text {own }}$. Hence, since $\bar{X}^{C} \subset \bar{X}^{G}, W_{F, 7,13} \leq$ $W_{G}$.

I define the operator vector valued operator $T$ based on equations 1, 11, 12, 17, 18, 21 , 23 and 25 ,

Lemma $13 T$ is a contraction mapping with modulus $\beta$.

Proof In order to prove that $T$ is a contract mapping I appeal to Blackwell's sufficient conditions:

1. Self-map: $T V \subset \mathcal{V}$. In order to show this first note that $W_{C}^{j}$ are all continuous in their first argument, the convex combination of two continuous functions is continuous and the maximum of two continuous functions is continuous. The boundedness property 40 is satisfied by the boundedness of $W_{C}^{j}$. That $T V$ is increasing in $b^{\prime}, h^{\prime}$ and $y^{\prime}$ comes from the fact that all the $W_{C}^{j}$ are increasing in their first argument and that $W_{7}^{\text {liquidate }}$ is strictly increasing in $y$. By the same argument, $T V$ is decreasing in $m^{\prime}$. The monotonicity property (41) is satisfied by virtue of $W_{G} \geq W_{7,13, F}$ since the payoff in $V_{7,13, F}$ can always be achieved in $V_{G}$. 
2. Monotonicity: $\hat{V} \geq V \rightarrow T \hat{V} \geq T V$. For each $C \in \mathcal{C}, W_{C}^{j}(\cdot ; V)$ is increasing in $V$. Therefore, because the convex combination of two increasing functions is increasing and the maximum of two increasing functions is increasing $T \hat{V} \geq T V$.

3. Discounting: $T(V+k)=T V+\beta k$. Notice that for each $C \in \mathcal{C} W_{C}^{j}(\cdot ; V), W_{C}^{j}(\cdot ; V+k)=$ $W_{C}^{j}(\cdot ; V)+\beta k$, thus for each $C \in \mathcal{C}, T\left(V_{C}+k\right)=T V_{C}+\beta k$.

Since I have extended the domain of $W_{G}$, I must now verify that an agent will never make a choice such that he will have no feasible choices (i.e. for $W_{G}$ he would choose to file Chapter 7 bankruptcy rather than repay. First I prove that an agent will choose to go bankrupt rather than not go bankrupt and have zero consumption.

Lemma 14 Under Assumption 1, an agent with a good credit history will always choose to file for Chapter 7 bankruptcy rather than not and have zero consumption. Furthermore, an agent that chooses not to file for Chapter 7 bankruptcy always consumes a strictly positive amount.

Proof The utility from choosing not to file for Chapter 7 when the budget set is empty is bounded by $U(0, \underline{h})+\beta \bar{u} /(1-\beta)$. By choosing to file Chapter 7 the agent can guarantee lifetime utility of at least $u\left(\left(\underline{y}-p_{r} \underline{h}\right) / \lambda\right.$, underlineh $) /(1-\beta)$, which by Assumption 1 is strictly greater. To ensure that conditional on not going bankrupt agents consume a strictly positive amount, note that from the continuity of $U(\cdot, \cdot)$, there exists some $\tilde{c}>0$ such that $U(\tilde{c}, \underline{h})+\beta \bar{u} /(1-\beta)<U\left(\left(\underline{y}-p_{r} \underline{h}\right) / \lambda, \underline{h}\right) /(1-\beta)$, which implies that conditional on not going bankrupt an agent will consume at least $\tilde{c}$.

Proof of Proposition 1 The existence and uniqueness of the value functions is an immediate consequence of Lemma 13 and the Contraction Mapping Theorem. The monotonicity properties of the value functions and the effect of a bad credit score follow immediately from Lemmas 11 \& 12 .

If the period of punishment for Chapter 7 and Chapter 13 bankruptcy are the same length (i.e., $\alpha_{7}=\alpha_{13}$ ), a household with only exempt home equity $(\eta \leq \chi)$ will never choose to file for Chapter 13 bankruptcy.

Proposition 1 Chapter 13 Bankruptcy Characterization

If $\alpha_{7}=\alpha_{13}$ a household with only exempt home equity, $\eta \leq \chi$, the household will never choose to file Chapter 13 bankruptcy.

The intuition for the result is straightforward. If the household has only exempt home equity, it does not lose any assets by filing for Chapter 7 bankruptcy. However, if it files for Chapter 13 bankruptcy, it keeps the same level of assets, but commits to pay a fraction of its income for the duration of the punishment period. Therefore, if the period of punishment is identical, then in all states of the world the household will have higher resources if it files for Chapter 7 over Chapter 13. While this is a strong result, when relating it to the real world, it should be seen as a statement that when a household has only exempt assets it would never choose to file Chapter 13 (in the model the statements are equivalent, since home equity is the only exempt asset).

The proof of Proposition 2 is an extension of Chatterjee et al. (2007). I first prove six lemmas. 
Lemma 15 Let $\hat{y} \in Y \backslash \overline{\mathcal{B}}_{7, R}^{*}(b, z), y>\hat{y}$. If $y \in \overline{\mathcal{B}}_{7, R}^{*}(b, z)$, then the optimal consumption with $\hat{y}, c^{*}(b+\hat{y})>\hat{y}-p_{r} \underline{h}$.

Proof Since $\hat{y} \in Y \backslash \overline{\mathcal{B}}_{7, R}^{*}(b, z)$, the agent strictly prefers not declaring Chapter 7 bankruptcy, i.e. either:

$$
U\left(c^{*}(b+\hat{y}), \underline{h}\right)+\beta \mathbb{E} V_{G}^{r e n t}\left(X^{* *}\right)>U\left(\hat{y}-p_{r} \underline{h}, \underline{h}\right)+\beta \mathbb{E} V_{7}^{r e n t}\left(X^{\prime}\right)
$$

or

$$
U\left(c^{*}(b+\hat{y}), h^{* *}\right)+\beta \mathbb{E} V_{G}^{\text {own }}\left(X^{\prime *}\right)>U\left(\hat{y}-p_{r} \underline{h}, \underline{h}\right)+\beta \mathbb{E} V_{7}^{r e n t}\left(X^{\prime}\right)
$$

Let $\epsilon=y-\hat{y}$. The choices: $\check{c}=c^{*}\left(\eta+b_{F}+\hat{y}\right)+\epsilon, \check{b^{\prime}}=b^{\prime *}, \check{h}^{\prime}=h^{\prime *}, \check{m}^{\prime}=m^{\prime *}$ were feasible choices with resources $y+b$, but were not chosen since $y \in \overline{\mathcal{B}}_{7, R}^{*}(b, z)$ (where the starred variables are the optimal choices under endowment $\hat{y}$ ), therefore either:

$$
U(\check{c}, \underline{h})+\beta \mathbb{E} V_{G}^{r e n t}\left(X^{\prime *}\right) \leq U\left(y-p_{r} \underline{h}, \underline{h}\right)+\beta \mathbb{E} V_{7}^{r e n t}\left(X^{\prime}\right)
$$

or

$$
U\left(\check{c}, h^{\prime *}\right)+\beta \mathbb{E} V_{G}^{\text {own }}\left(X^{\prime *}\right) \leq U\left(y-p_{r} \underline{h}, \underline{h}\right)+\beta \mathbb{E} V_{7}^{r e n t}\left(X^{\prime}\right)
$$

Subtracting equations (49) and (51) I obtain:

$$
U\left(\hat{y}+\epsilon-p_{r} \underline{h}, \underline{h}\right)-U\left(\hat{y}-p_{r} \underline{h}, \underline{h}\right)>U\left(c^{*}(b+\hat{y})+\epsilon, \underline{h}\right)-U\left(c^{*}(b+\hat{y}), \underline{h}\right)
$$

and subtracting equations $(50)$ and $(52)$ I obtain:

$$
U\left(\hat{y}+\epsilon-p_{r} \underline{h}, \underline{h}\right)-U\left(\hat{y}-p_{r} \underline{h}, \underline{h}\right)>U\left(c^{*}(b+\hat{y})+\epsilon, h^{\prime *}\right)-U\left(c^{*}(b+\hat{y}), h^{\prime *}\right)
$$

which from the strict concavity of $U(\cdot)$ implies that $c^{*}(b+\hat{y})>\hat{y}-p_{r} \underline{h}$. The portfolio choice is unchanged for the household conditional on Chapter 7 bankruptcy, thus $X^{\prime}$ is the same across (51), 52), (53) and (54).

Lemma 16 Let $\hat{y} \in Y \backslash \overline{\mathcal{B}}_{7, F}^{*}(b, z), y>\hat{y}$. If $y \in \overline{\mathcal{B}}_{7, F}^{*}(b, z)$, then the optimal consumption with $\hat{y}, c^{*}(b+\hat{y})>\hat{y}-p_{r} \underline{h}$.

Proof Omitted. The proof is essentially identical to the previous.

Lemma 17 Let $\hat{y} \in Y \backslash \overline{\mathcal{B}}_{7, R}^{*}(b, z), y<\hat{y}$. If $y \in \overline{\mathcal{B}}_{7, R}^{*}(b, z)$, then the optimal consumption with $\hat{y}, c^{*}(b+\hat{y})<\hat{y}-p_{r} \underline{h}$.

Proof Omitted. The proof is essentially identical to the previous.

Lemma 18 Let $\hat{y} \in Y \backslash \overline{\mathcal{B}}_{7, F}^{*}(b, z), y<\hat{y}$. If $y \in \overline{\mathcal{B}}_{7, F}^{*}(b, z)$, then the optimal consumption with $\hat{y}, c^{*}(b+\hat{y})<\hat{y}-p_{r} \underline{h}$.

Proof Omitted. The proof is essentially identical to the previous.

Lemma 19 Let $\hat{y} \in Y \backslash \overline{\mathcal{B}}_{7, \theta=1}^{*}(b, \eta, \xi, z), y>\hat{y}$. If $y \in \overline{\mathcal{B}}_{7, \theta=1}^{*}(b, \eta, \xi, z)$, then the optimal consumption with $\hat{y}, c^{*}(b+\eta+\hat{y})>\hat{y}-p_{r} \underline{h}$. 
Proof Omitted. The proof is essentially identical to the previous. Since the household has been hit by the moving shock the pertinent resources are home equity and non-exempt home equity.

Lemma 20 Let $\hat{y} \in Y \backslash \overline{\mathcal{B}}_{7, \theta=1}^{*}(b, \eta, \xi, z), y<\hat{y}$. If $y \in \overline{\mathcal{B}}_{7, \theta=1}^{*}(b, \eta, \xi, z)$, then the optimal consumption with $\hat{y}, c^{*}(b+\eta+\hat{y})<\hat{y}-p_{r} \underline{h}$.

Proof Omitted. The proof is essentially identical to the previous.

Lemma 21 Let $\hat{y} \in Y \backslash \overline{\mathcal{B}}_{7, \theta=0}^{*}(b, h, m, \omega, z), y<\hat{y}$. If $y \in \overline{\mathcal{B}}_{7, \theta=0}^{*}(b, h, m, \omega, z)$, then if the household has only exempt home equity, i.e. $\eta \leq \xi$, the optimal consumption with $\hat{y}$, $c^{*}(b, h, m, \omega, z)<\hat{y}-r_{m} m-\mu_{h} p_{h} h$, otherwise $c^{*}(b, h, m, \omega, z)<\hat{y}-p_{r} \underline{h}$.

Proof First consider the case where the household has non-exempt home equity, if it files for Chapter 7 bankruptcy it has to liquidate the home.

The proof is essentially identical to the previous ones, but there are additional cases to consider. Since $\hat{y} \in Y \backslash \overline{\mathcal{B}}_{7, \theta=0}^{*}(b, h, m, \omega, z)$, the agent strictly prefers not declaring Chapter 7 bankruptcy, i.e. either the household becomes a renter conditional on not defaulting:

$$
U\left(c^{*}(b+\eta+\hat{y}), \underline{h}\right)+\beta \mathbb{E} V_{G}^{r e n t}\left(X^{\prime *}\right)>U\left(\hat{y}-p_{r} \underline{h}, \underline{h}\right)+\beta \mathbb{E} V_{7}^{r e n t}\left(X^{\prime}\right)
$$

or the household sells its home and buys a new one:

$$
U\left(c^{*}(b+\eta+\hat{y}), h^{\prime *}\right)+\beta \mathbb{E} V_{G}^{o w n}\left(X^{\prime *}\right)>U\left(\hat{y}-p_{r} \underline{h}, \underline{h}\right)+\beta \mathbb{E} V_{7}^{r e n t}\left(X^{\prime}\right)
$$

or the household keeps its home:

$$
U\left(c^{*}(b+\hat{y}, m, h), h\right)+\beta \mathbb{E} V_{G}^{\text {own }}\left(X^{\prime *}\right)>U\left(\hat{y}-p_{r} \underline{h}, \underline{h}\right)+\beta \mathbb{E} V_{7}^{r e n t}\left(X^{\prime}\right)
$$

From here the remainder of the steps are unchanged.

When the household has only exempt home equity the choices when not defaulting remain unchanged, but the bankruptcy choices change:

$$
U\left(c^{*}(b+\eta+\hat{y}), \underline{h}\right)+\beta \mathbb{E} V_{G}^{r e n t}\left(X^{*}\right)>U\left(\hat{y}-r_{m} m-\mu_{h} p_{h} h, h\right)+\beta \mathbb{E} V_{7}^{\text {own }}\left(X^{\prime}\right)
$$

or the household sells its home and buys a new one:

$$
U\left(c^{*}(b+\eta+\hat{y}), h^{\prime *}\right)+\beta \mathbb{E} V_{G}^{\text {own }}\left(X^{\prime *}\right)>U\left(\hat{y}-r_{m} m-\mu_{h} p_{h} h, h\right)+\beta \mathbb{E} V_{7}^{\text {own }}\left(X^{\prime}\right)
$$

or the household keeps its home:

$$
U\left(c^{*}(b+\hat{y}, m, h), h\right)+\beta \mathbb{E} V_{G}^{o w n}\left(X^{*}\right)>U\left(\hat{y}-r_{m} m-\mu_{h} p_{h} h, h\right)+\beta \mathbb{E} V_{7}^{o w n}\left(X^{\prime}\right)
$$

Using the same differencing strategy as in the previous lemma and exploiting the strict concavity of the period utility function the same result obtains.

\section{Proof of Proposition 2}


1. (a) If $\overline{\mathcal{B}}_{7, R}^{*}(b, z)$ is non-empty let $\underline{y}^{B}=\inf \overline{\mathcal{B}}_{7, R}^{*}(b, z)$ and $\bar{y}^{B}=\sup \overline{\mathcal{B}}_{7, R}^{*}(b, z)$. These both exist from the Completeness Property of $\mathbb{R}$ since $\overline{\mathcal{B}}_{7, R}^{*}(b, z) \subseteq Y \subset \mathbb{R}$. If they're

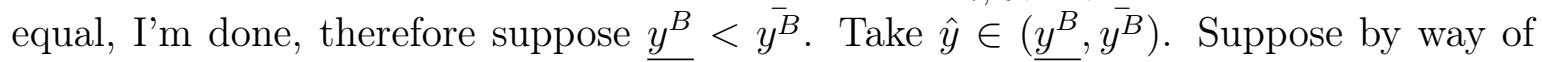
contradiction that $\hat{y} \notin \overline{\mathcal{B}}_{7, R}^{*}(b, z)$. Now, there exists a $y \in \overline{\mathcal{B}}_{7, R}^{*}(b, z)$ such that $y>\hat{y}$ (if not $\overline{y^{B}}=\hat{y}$, contradicting that $\left.\hat{y} \in\left(y^{B}, \bar{y}^{B}\right)\right)$. Thus, from Lemma $15, c^{*}(b+\hat{y})>\hat{y}$. By the same argument there exists a $y \in \overline{\mathcal{B}}_{7, R}^{*}(b, z)$ such that $y<\hat{y}$, but from Lemma 17 this implies $c^{*}(b+\hat{y})<\hat{y}$, a contradiction. The closedness comes from the continuity of $W_{G}^{r e n t}$ and $U(\cdot, \cdot)$.

(b)-(d) Identical to above.

2. Suppose $y \in \overline{\mathcal{B}}_{7, R}^{*}(\hat{b}, z)$. Take $b<\hat{b}$. Since $W_{G}^{\text {rent }}$ is increasing in the first argument, $W_{G}^{\text {rent }}(b+y, z) \leq W_{G}^{\text {rent }}(\hat{b}+y, z)$. However, since $y \in \overline{\mathcal{B}}_{7, R}^{*}(\hat{b}, z)$ this implies that $W_{G}^{\text {rent }}(\hat{b}+y, z) \leq W_{7}^{\text {liquidate }}(0, y, z) \Rightarrow W_{G}^{\text {rent }}(b+y, z) \leq W_{7}^{\text {liquidate }}(0, y, z) \Rightarrow y \in$ $\overline{\mathcal{B}}_{7, R}^{*}(b, z)$, which implies $\overline{\mathcal{B}}_{7, R}^{*}(\hat{b}, z) \subseteq \overline{\mathcal{B}}_{7, R}^{*}(b, z)$. A similar argument can be made for $\overline{\mathcal{B}}_{7, F}^{*}$. For $\overline{\mathcal{B}}_{7, \theta=1}^{*}$ again a similar argument can be made with $W_{7}^{\text {liquidate }}$ evaluated at $(\eta-\xi, y, z)$. The same holds for $\overline{\mathcal{B}}_{7, \theta=0}^{*}$ when $\eta>\xi$, whereas when $\eta \leq \xi$ the relevant comparison is with $W_{7}^{k e e p}(h, m, y, \omega, z)$.

\section{Proof of Proposition 3}

(a) Suppose $y \in \overline{\mathcal{B}}_{7, \theta=1}^{*}\left(b, \eta, \xi_{1}, z\right)$. Take $\xi_{2}<\xi_{1}$. Since $W_{7}^{\text {liquidate }}$ is increasing in the first argument $W_{7}^{\text {liquidate }}\left(\eta-\xi_{1}, y, z\right) \leq W_{7}^{\text {liquidate }}\left(\eta-\xi_{2}, y, z\right)$. However, since $y \in$ $\overline{\mathcal{B}}_{7, \theta=1}^{*}\left(b, \eta, \xi_{1}, z\right)$ this implies that $\max \left\{W_{G}^{\text {buy }}(b+\eta+y, z), W_{G}^{\text {rent }}(b+\eta+y, z), W_{13}^{\text {rent }}(\eta+\right.$ $(1-\phi) y, \phi, z)\} \leq W_{\mathcal{F}}^{B}\left(\eta-\xi_{1}^{\prime}, y, z\right)$, which implies that $y \in \overline{\mathcal{B}}_{7, \theta=1}^{*}\left(b, \eta, \xi_{2}, z\right)$.

(b) Suppose $y \in \overline{\mathcal{B}}_{7, \theta=1}^{*}(b, \eta, \xi, z)$. Take $x>0$. Since $W_{7}^{\text {liquidate }}$ is increasing in its first argument, $W_{7}^{\text {liquidate }}(\eta+x-\xi, y, z) \geq W_{7}^{\text {liquidate }}(\eta-\xi, y, z)$. However, since $y \in$ $\overline{\mathcal{B}}_{7, \theta=1}^{*}(b, \eta, \xi, z)$ this implies that $\max \left\{W_{G}^{\text {rent }}(\eta+y+b, z), W_{G}^{\text {buy }}(\eta+y+b, z), W_{13}^{r e n t}(\eta+\right.$ $(1-\phi) y, z)\} \leq W_{7}^{\text {liquidate }}(\eta-\xi, y, z)$, and $\max \left\{W_{G}^{\text {rent }}(\eta+y+b, z), W_{G}^{\text {buy }}(\eta+y+b, z)\right\}=$ $\max \left\{W_{G}^{r e n t}((\eta+x)+y+(b-x), z), W_{G}^{b u y}((\eta+x)+y+(b-x), z)\right.$, therefore either filing for Chapter 13 bankruptcy is still less desirable than Chapter $7 W_{13}^{r e n t}(\eta+x+(1-\tilde{\phi}) y, z) \leq$ $\left.W_{13}^{\text {rent }}(\eta+(1-\phi) y, z) \leq W_{7}^{\text {liquidate }}(\eta+x-\xi, y, z)\right\}$ and therefore $y \in \overline{\mathcal{B}}_{7}^{*}(b-x, \eta+x, \xi, z)$, or $W_{13}^{\text {rent }}(\eta+x+(1-\tilde{\phi}) y, z)>\max \left\{W_{G}^{\text {rent }}(\eta+y+b, z), W_{G}^{\text {buy }}(\eta+y+b, z), W_{7}^{\text {liquidate }}(\eta+\right.$ $x-\xi, y, z)\}$ and the household files for Chapter 13 bankruptcy, i.e. $y \in \overline{\mathcal{B}}_{13, \theta=1}^{*}$.

(c) Suppose $y \notin \overline{\mathcal{B}}_{7}^{*}(b, \eta, \xi, z)$, where $\xi>0$. Take $x>0$. Since $W_{G}^{\text {buy,rent }}$ is increasing in the first argument, $W_{G}^{\text {buy,rent }}(b+\eta+x+y, z) \geq W_{G}^{\text {buy,rent }}\left(b_{F}+\eta+y, z\right)$. Note that since $\xi>0$, the additional home equity is forfeited in Chapter 7 bankruptcy, $W_{7}^{\text {liquidate }}((\eta+x)-(\xi+x), y, z)=W_{G}^{\text {liquidate }}(\eta-\xi, y, z)$. Thus, since $y \notin \overline{\mathcal{B}}_{7, \theta=1}^{*}(b, \eta, \xi, z)$ this implies that $W_{G}^{\text {rent,buy }}(b+\eta+x+y, z) \geq W_{G}^{\text {rent,buy }}(b+\eta+y, z) \geq W_{7}^{\text {liquidate }}(\eta-\xi, y, z)$, which implies that $y \notin \overline{\mathcal{B}}_{7, \theta=1}^{*}(b, \eta+x, \xi+x, z)$.

(d) This follows directly from Proposition 1 and the monotonicity of the budget set. 


\section{Supplementary Tables}


Table 1: Externally Calibrated Parameters

\begin{tabular}{|c|c|c|}
\hline Parameter & Value & Target \\
\hline \multicolumn{3}{|l|}{ Income Process } \\
\hline Persistence, $\rho_{z}$ & 0.98 & \\
\hline Std. of persistent shocks, $\sigma_{\nu_{z}}$ & 0.3 & Income process (Storesletten et al, 2004) \\
\hline Std. of transitory shocks $\sigma_{\varepsilon_{y}}$ & 0.245 & \\
\hline House Price Process Persistence, $\rho_{h}$, & 0.97 & Nagaraja et al, 2009 \\
\hline Std. of persistent shocks, $\sigma_{\nu_{h}}$ & 0.08 & OFHEO HPI \\
\hline Std. of transitory shocks, $\sigma_{\varepsilon_{h}}$ & 0.005 & OFHEO HPI \\
\hline \multicolumn{3}{|l|}{ Legal Technology } \\
\hline Foreclosure technology, $\gamma$ & 0.78 & Foreclosure Sale Loss \\
\hline Bankruptcy technology, $\zeta$ & 0.52 & Distributions to Creditors \\
\hline Clean credit history, $\alpha_{7}$ & 0.2 & File for Chapter 7 every 6 years \\
\hline Clean credit history, $\alpha_{13}$ & 0.2 & Chapter 13 5-year repayment \\
\hline Clean credit history, $\alpha_{F}$ & 0.5 & Fair Issac \\
\hline $\begin{array}{l}\text { Probability of } \\
\text { deficiency judgment, } \psi\end{array}$ & $0.10 / 0.15$ & See text \\
\hline \multicolumn{3}{|l|}{ Housing Technology } \\
\hline Housing maintenance & $2 \%$ & Depreciation + taxes \\
\hline Moving shock & 0.2 & Median tenure \\
\hline \multicolumn{3}{|l|}{ Interest Rates } \\
\hline Risk-free rate, $r_{b}$ & 0.01 & Risk-free rate \\
\hline Cost of issuing mortgages, $r_{m}$ & $10 \mathrm{BP}$ & Mortgage administration cost \\
\hline Cost of issuing unsecured debt, $r_{b}$ & $50 \mathrm{BP}$ & Unsecured administration cost \\
\hline \multicolumn{3}{|l|}{ Preferences } \\
\hline Cobb-Douglas parameter, $\theta$ & 0.8590 & Housing share of consumption $14.1 \%$ \\
\hline
\end{tabular}


Table 2: Legal Environments Considered

\begin{tabular}{|c|c|c|c|c|}
\hline States & $\begin{array}{l}\text { Homestead } \\
\text { Exemption }\end{array}$ & Recourse & $\begin{array}{l}\text { Median HH } \\
\text { Income }\end{array}$ & Weight \\
\hline Washington, N. Carolina & 0.64 & No & 42334 & 0.053 \\
\hline California, Alaska, N. Dakota & 1.58 & No & 47211 & 0.112 \\
\hline Minnesota, Arizona, Montana & 3.33 & No & 42154 & 0.050 \\
\hline $\begin{array}{l}\text { Maryland, Ohio, Georgia, Illinois, } \\
\text { Tennessee, Indiana, Virginia } \\
\text { Kentucky, S. Carolia, Alabama }\end{array}$ & 0.23 & Yes & 42146 & 0.248 \\
\hline $\begin{array}{l}\text { Michigan, Missouri, Louisiana, } \\
\text { New York, Wyoming, New Jersey, } \\
\text { Nebraska, Michigan, Pennsylvania, } \\
\text { Hawaii, Oregon, West Virginia, } \\
\text { Utah, Wisconsin, Arkansas, } \\
\text { Delaware, Colorado, Idaho }\end{array}$ & 0.677 & Yes & 42650 & 0.305 \\
\hline $\begin{array}{l}\text { Massachusetts, New Mexico, Maine, } \\
\text { New Hampshire, Mississippi, Nevada, } \\
\text { Connecticut, Vermont, Rhode Island }\end{array}$ & 3.65 & Yes & 44872 & 0.075 \\
\hline $\begin{array}{l}\text { Florida, Texas, Kansas } \\
\text { Oklahoma, S. Dakota, D.C. }\end{array}$ & $\infty$ & Yes & 38944 & 0.158 \\
\hline
\end{tabular}

Table 3: State Results - Recourse

\begin{tabular}{lc|c|c|c}
\hline & $\begin{array}{c}\text { Maryland } \\
\chi^{s}=0.23\end{array}$ & $\begin{array}{c}\text { Michigan } \\
\chi^{s}=0.68\end{array}$ & $\begin{array}{c}\text { Massachusetts } \\
\chi^{s}=3.7\end{array}$ & $\begin{array}{c}\text { Florida } \\
\chi^{s}=\infty\end{array}$ \\
\hline Debt & -1.85 & -1.74 & -1.80 & -1.81 \\
Bonds, $B_{+}$ & 0.34 & 0.43 & 0.53 & 0.46 \\
Unsecured debt, $B_{-}$ & -0.16 & -0.10 & -0.04 & -0.01 \\
Mortgages $M$ & 1.69 & 1.65 & 1.76 & 1.8 \\
Bankruptcy rate & $1.34 \%$ & $1.05 \%$ & $0.87 \%$ & $0.80 \%$ \\
Foreclosure rate & $0.3 \%$ & $0.4 \%$ & $0.8 \%$ & $0.8 \%$ \\
In debt & $4.4 \%$ & $3.7 \%$ & $4.2 \%$ & $4.3 \%$ \\
Fraction of households & $40 \%$ & $23 \%$ & $26 \%$ & $27 \%$ \\
$\quad$ with Unsecured Debt & & & & \\
\hline
\end{tabular}


Table 4: State Results - No Recourse

\begin{tabular}{lc|c|c}
\hline & $\begin{array}{c}\text { Washington } \\
\chi^{s}=0.64\end{array}$ & $\begin{array}{c}\text { California } \\
\chi^{s}=1.57\end{array}$ & $\begin{array}{c}\text { Minnesota } \\
\chi^{s}=3.32\end{array}$ \\
\hline Housing, $H$ & 3.40 & 3.49 & 3.44 \\
Debt & -1.72 & -1.88 & -1.80 \\
Bonds, $B_{+}$ & 0.39 & 0.45 & 0.49 \\
Unsecured debt, $B_{-}$ & -0.12 & -0.07 & -0.02 \\
Mortgages $M$ & 1.61 & 1.81 & 1.78 \\
Bankruptcy rate & $1.12 \%$ & $0.95 \%$ & $0.80 \%$ \\
Foreclosure rate & $0.4 \%$ & $0.8 \%$ & $0.8 \%$ \\
In debt & $3.6 \%$ & $4.3 \%$ & $4.2 \%$ \\
Fraction of households & $21 \%$ & $24 \%$ & $27 \%$ \\
$\quad$ with Unsecured Debt & & & \\
\hline
\end{tabular}

Table 5: State Level Implications of BAPCPA

\begin{tabular}{|c|c|c|c|c|}
\hline \multirow{2}{*}{ State } & \multicolumn{2}{|c|}{ Bankruptcy Rates } & \multicolumn{2}{|c|}{ Chapter 13 Share } \\
\hline & Baseline & BAPCPA & Baseline & BAPCPA \\
\hline Maryland & $1.34 \%$ & $0.83 \%$ & $9 \%$ & $17 \%$ \\
\hline Michigan & $1.05 \%$ & $0.77 \%$ & $10 \%$ & $16 \%$ \\
\hline Massachusetts & $0.87 \%$ & $0.68 \%$ & $3 \%$ & $18 \%$ \\
\hline Florida & $0.80 \%$ & $0.72 \%$ & $0 \%$ & $14 \%$ \\
\hline Washington & $1.12 \%$ & $0.73 \%$ & $10 \%$ & $18 \%$ \\
\hline California & $0.94 \%$ & $0.61 \%$ & $2 \%$ & $10 \%$ \\
\hline Minnesota & $0.80 \%$ & $0.65 \%$ & $1 \%$ & $16 \%$ \\
\hline
\end{tabular}

Table 6: Borrower Characteristics and Interest Rates intrate $_{i}=\beta_{0}+\beta_{1} \log \left(y_{i}\right)+\beta_{2} \log \left(\eta_{i}\right)+\beta_{3} \mathbf{1}_{\text {HighExemption }}+\epsilon_{i}$

\begin{tabular}{lcc}
\hline \multicolumn{1}{c}{ Variable } & Coefficient & (Std. Err.) \\
\hline $\log ($ Income $)$ & $-3.81^{* * *}$ & $(0.999)$ \\
$\log$ (Home equity) & $-0.30^{* *}$ & $(0.134)$ \\
High Exemption Dummy & $2.75^{*}$ & $(1.639)$ \\
\hline$N$ & 11,055 \\
$\mathrm{R}^{2}$ & 0.003 \\
\hline \multicolumn{3}{c}{$* * *$ indicates significance at 1\% level } \\
$* *$ indicates significance at $5 \%$ level \\
$*$ indicates significance at 10\% level
\end{tabular}




\section{Supplementary Figures}




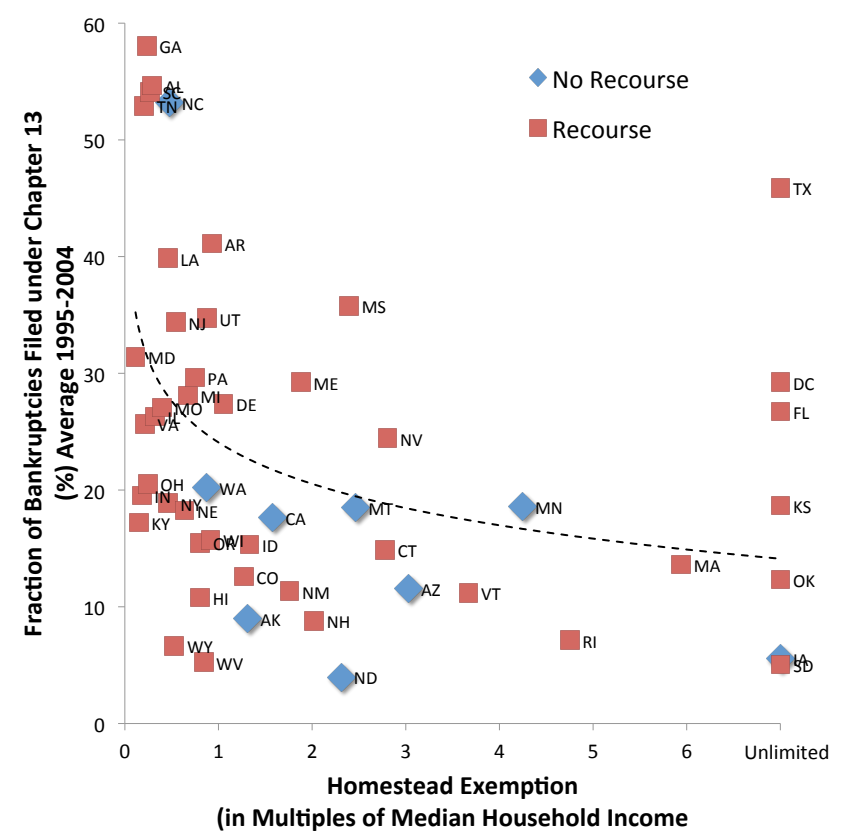

Figure 1: Bankruptcy and Foreclosure Rates Across States. Notes: The homestead exemptions in terms of median income is calculated by state law for the homestead exemption in the year 2000 and median household income from the Census in 2000. Average state bankruptcy rates 1995-2004 are computed using bankruptcy filings from the American Bankruptcy Institute and the number of households in each state from the Census. Average state foreclosure rates 1994-1999 are computed from the Mortgage Banker Association's quarterly National Delinquency Survey from 1994-1999. The dashed lines are smoothed versions of the data. 


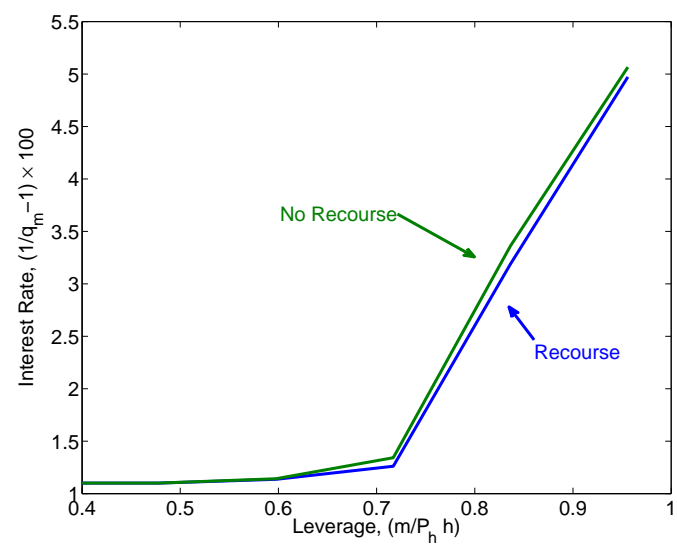

(a) Mortgage Interest Rates

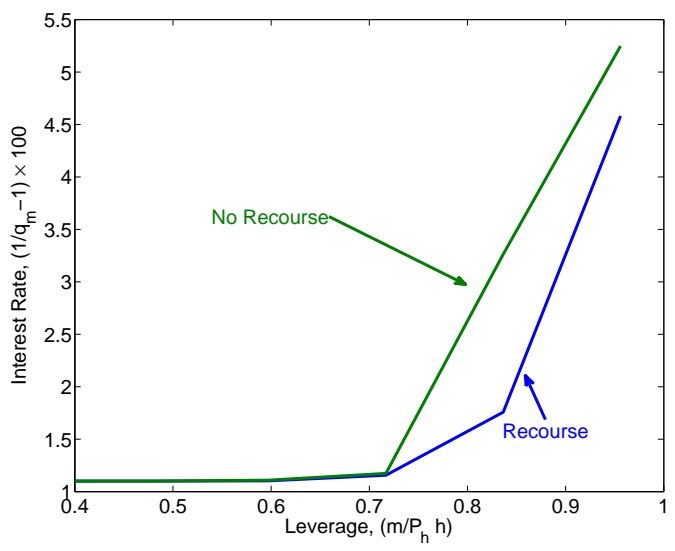

(b) Unsecured Interest Rates

Figure 2: Mortgage interest rates are plotted as a function of leverage, $\frac{m}{p_{h} h}$, for identical households in recourse and no-recourse states. Notes: In the left panel the household has median income, a house worth 3.5 times median income and no savings or unsecured debt. In the right panel the household has 2.5 times median income, a house worth 6 times median income and no unsecured debt or savings. 
Notes: The unsecured interest rate is plotted as a function of leverage, $\kappa=\frac{m}{p_{h} h}$, and unsecured debt $b$, for a household that owns a house worth roughly 3.5 times median income, that has median income, is in a recourse state with an exemption of $\$ 30,000$

Notes: The mortgage interest rate is plotted as a function of leverage, $\kappa=\frac{m}{p_{h} h}$, and unsecured debt $b$, for a household that owns a house worth roughly 3.5 times median income, that has median income, is in a recourse state with an exemption of $\$ 30,000$ 


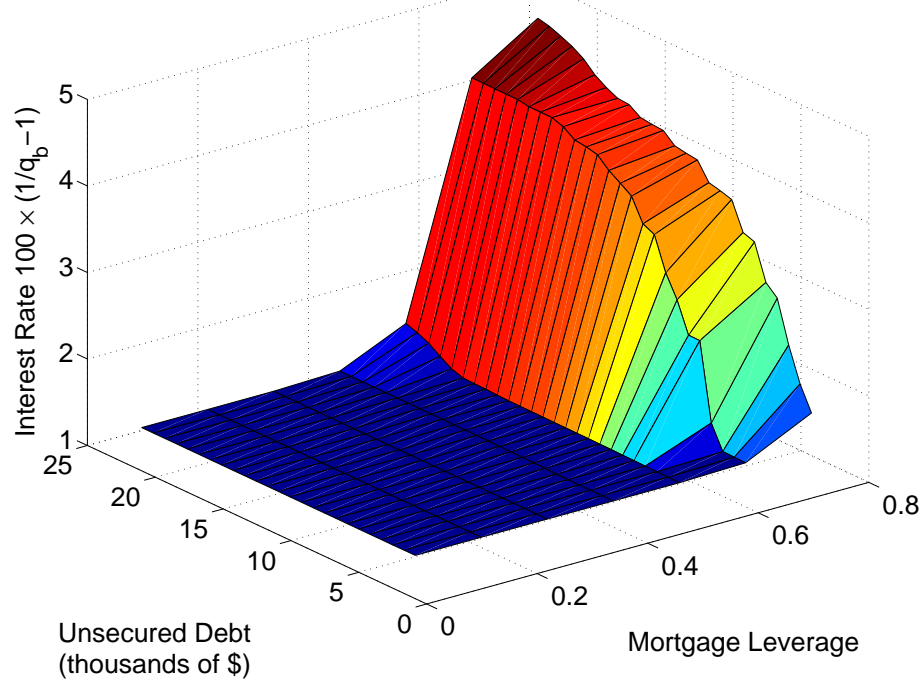

Figure 3: Model unsecured interest rates

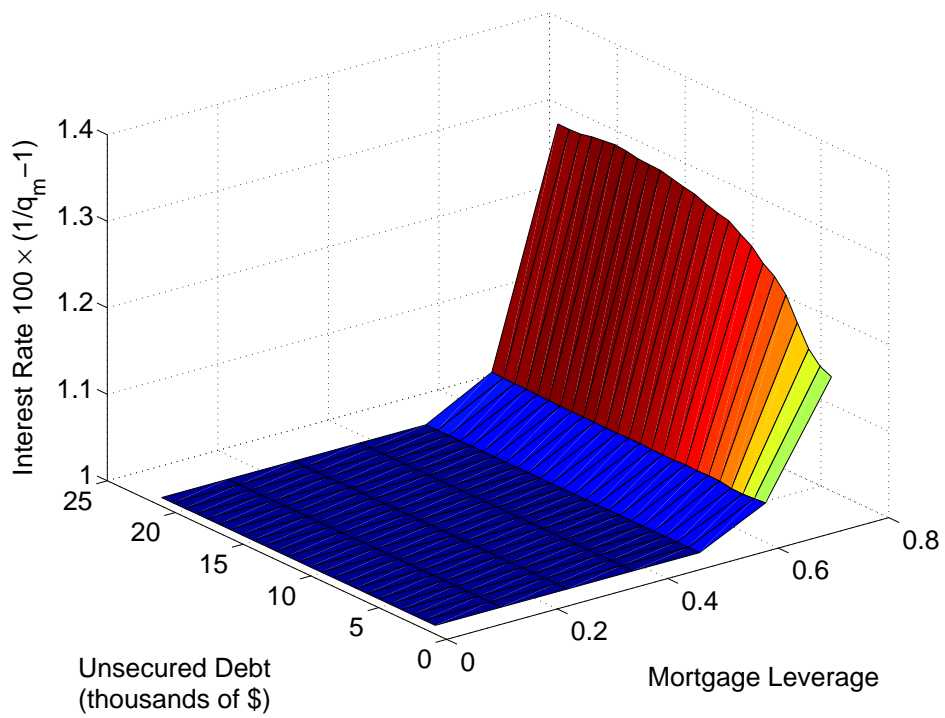

Figure 4: Model mortgage interest rates 


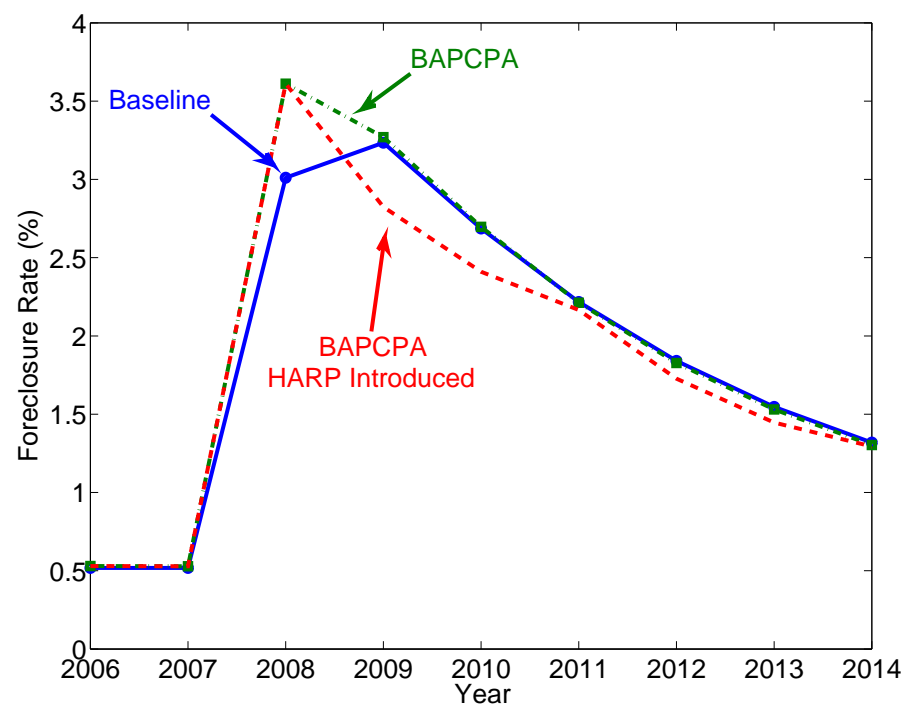

Figure 5: Effects of BAPCPA and HARP on foreclosures following an aggregate price drop

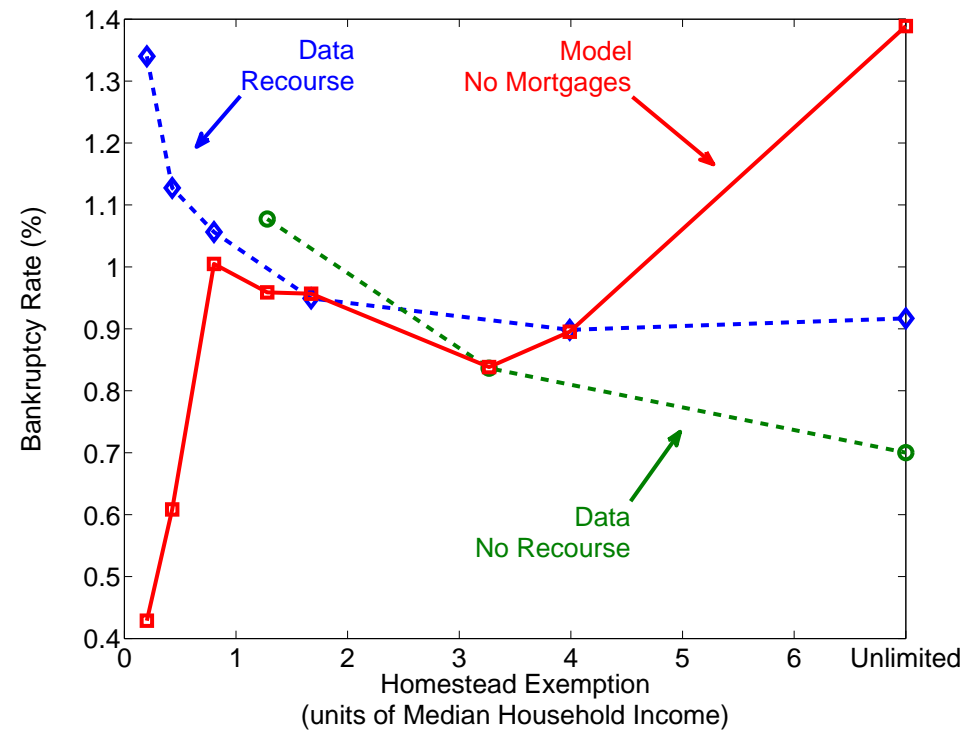

Figure 6: Data vs counterfactual model without mortgages and foreclosure. 


\section{Counterfactual Model without Mortgages}

To illustrate the importance of studying foreclosure and bankruptcy together in order to capture the cross-state variation in bankruptcy rate, I conduct the following thought experiment: would a modified model without mortgages and foreclosure capture the cross-state variation? To answer this question, I re-solve the model for all 50 states without mortgages. I plot the conditional means in Figure 6. This version of the model does not reproduce the observed negative relationship between bankruptcy rates and the homestead exemption. In fact, it generates a positive relationship between the homestead exemption and the bankruptcy rate. This result is reminiscent of the findings of Athreya (2006), who modeled exemptions without the possibility of default on secured debt. Further, exlcuding states with an unlimited exemption, it also generates a positive relationship between the homestead exemption and the Chapter 13 bankruptcy rate. Households are using credit card debt partially to finance the purchases of homes. The bankruptcy rate is lower in low exemption states because households stand to lose significant home equity if they file for Chapter 7 bankruptcy. The increase in the bankruptcy rate when the exemption increases is almost entirely driven by an increase in Chapter 13 bankruptcy. Filing for Chapter 13 allows them to partially repay what was owed over five years. The Chapter 13 filing rate is low in low exemption states because of the legal restriction that creditors must receive at least as much payment under Chapter 13 as they would have if non-exempt assets were liquidated in Chapter 7. Thus, households with significant non-exempt home equity (concentrated in low-exemption states) are precluded from filing for Chapter 13 when income is low. This counterfactual analysis highlights the importance of modeling bankruptcy and foreclosure together. 


\section{Computational Details}

In order to calibrate the model I employ a nested fixed point algorithm to match relevant moments from the model with the data. Solving the model is a computational challenge because of the complexity of the fixed point problem. With long-term mortgage debt, in order to solve the recursive functional equation for the price requires forecasting future mortgage and unsecured debt choices, in addition to default decisions. Those optimal policy choices respond to changes in both the mortgage and unsecured interest rates. The introduction of the two iid shocks in income and house prices helps smooth out the policy choices of households, to help prevent large changes in the optimal choice of $m^{\prime}$ or $b^{\prime}$ in response to small changes in prices which could lead to cycling. I discretize the state space and the choice parameters.

The outline of the algorithm is as follows:

1. Loop 1 - Guess a vector of the structural parameters $\Theta^{0}$

(a) Loop 2 - Make an initial guess for the price schedules $q_{b}^{0}$ and $q_{m}^{0}$

(b) Compute the policy choice $\left(\breve{b}^{\prime}, \breve{h}^{\prime}, \breve{m}^{\prime}\right)$ that yields the maximal resources in the current period, and denote it by $\breve{a}$.

i. Loop 3 - Make an initial guess for $W^{0}$ on the domain $[\breve{a}-\underline{c}, \bar{a}]$, and define $v^{0}$ for $a<\breve{a}-\underline{c}$ as $u(\underline{c})+\beta \bar{u} /(1-\beta)$, where $\underline{c}$ is a minimal consumption level.

ii. Compute $\mathbb{E}_{\delta^{\prime}, y^{\prime}, z^{\prime}} V^{H}\left(b^{\prime}, h^{\prime}, m^{\prime}, y^{\prime}, \delta^{\prime}, z^{\prime}\right)$ for each choice of $b^{\prime}, h^{\prime}, m^{\prime}$, and the implied discrete choies $B 7^{*}, B 13^{*}, f^{*}, S^{*}, R^{*}$ and $P^{*}$.

iii. Compute the new value functions, $W^{1}$, by maximization given $\mathbb{E}_{\delta^{\prime}, y^{\prime}, z^{\prime}} V\left(b^{\prime}, h^{\prime}, m^{\prime}, y^{\prime}, \delta^{\prime}, y^{\prime}\right)$

iv. Compute the portfolio policy functions

v. If $\left\|W^{1}-W^{0}\right\|<\epsilon_{W}$ end Loop 3, otherwise set $W^{0}=W^{1}$ and go to B.

(c) Given the default decisions $B^{*}$ and $f^{*}$, use Equations 32, 31, 26, 27, \& 28 to compute the new implied price schedules $q_{b}^{0}$ and $q_{m}^{0}$.

(d) If $\left\|q^{1}-q^{0}\right\|<\epsilon_{q}$ end Loop 2, otherwise set $q^{0}=\nu q^{0}+(1-\nu) q^{1}$ and go to (ii).

(e) Compute the invariant distribution $\mu$ over $A \times Z \times \times Y \mathcal{S}$.

2. Compute model moments $\mathcal{M}^{\mathrm{MODEL}}$.

3. If $\sum w_{i}\left(\mathcal{M}_{i}^{\mathrm{MODEL}}-\mathcal{M}_{i}^{\mathrm{DATA}}\right)^{2}<\epsilon_{\mathcal{M}}$ end Loop 1. Otherwise, return to 1 . 


\section{Foreclosure and Bankruptcy Information by State}

Table 7: Foreclosure Deficiency and Homestead

Bankruptcy Exemption by State

\begin{tabular}{|c|c|c|c|}
\hline State & Foreclosure Deficiency & Max Homestead Exemption & Federal Allowed \\
\hline Alabama & Yes & $5,000^{*}$ & No \\
\hline Alaska & No & 54,000 & No \\
\hline Arizona & No & 150,000 & No \\
\hline Arkansas & Yes & $17,425^{*}$ & Yes \\
\hline California & No & $50,000^{\dagger}$ & No \\
\hline Colorado & Yes & 45,000 & No \\
\hline Connecticut & Yes & 75,000 & Yes \\
\hline Delaware & Yes & 50,000 & No \\
\hline D.C. & Yes & $17,425^{*}$ & Yes \\
\hline Florida & Yes & $\infty$ & No \\
\hline Georgia & Yes & $10,000^{*}$ & No \\
\hline Hawaii & Yes & $17,425^{*}$ & Yes \\
\hline Idaho & Yes & 104,471 & No \\
\hline Illinois & Yes & $7,500^{*}$ & No \\
\hline Indiana & Yes & 7,500 & No \\
\hline Iowa & No & $\infty$ & No \\
\hline Kansas & Yes & $\infty$ & No \\
\hline Kentucky & Yes & 5,000 & No \\
\hline Louisiana & Yes & 25,000 & No \\
\hline Maine & Yes & 35,000 & No \\
\hline Maryland & Yes & 0 & No \\
\hline Massachusetts & Yes & 100,000 & Yes \\
\hline Michigan & Yes & $17,425^{*}$ & Yes \\
\hline Minnesota & No & 200,000 & Yes \\
\hline Mississippi & Yes & 75,000 & No \\
\hline Missouri & Yes & 15,000 & No \\
\hline Montana & No & 100,000 & No \\
\hline Nebraska & Yes & 12,500 & No \\
\hline Nevada & Yes & 550,000 & No \\
\hline New Hampshire & Yes & 100,000 & No \\
\hline New Jersey & Yes & $17,425^{*}$ & Yes \\
\hline New Mexico & Yes & $30,000^{*}$ & Yes \\
\hline New York & Yes & 50,000 & No \\
\hline North Carolina & No & 18,500 & No \\
\hline North Dakota & No & 80,000 & No \\
\hline Ohio & Yes & 5,000 & No \\
\hline Oklahoma & Yes & $\infty$ & No \\
\hline
\end{tabular}


Table 7 - Continued

\begin{tabular}{lccc}
\hline \hline State & Foreclosure Deficiency & Max Homestead Exemption & Federal Allowed \\
\hline Oregon & Yes & $25,000^{\ddagger}$ & No \\
Pennsylvania & Yes & $17,425^{*}$ & Yes \\
Rhode Island & Yes & 200,000 & Yes \\
South Carolina & Yes & $17,425^{*}$ & Yes \\
South Dakota & Yes & 30,000 & No \\
Tennessee & Yes & $5,000^{\dagger}$ & No \\
Texas & Yes & $\infty$ & Yes \\
Utah & Yes & $20,000^{*}$ & No \\
Vermont & Yes & 75,000 & Yes \\
Virginia & Yes & $5,000^{*}$ & No \\
Washington & No & 40,000 & Yes \\
West Virginia & Yes & 25,000 & No \\
Wisconsin & Yes & $40,000^{*}$ & Yes \\
Wyoming & Yes & $10,000^{*}$ & No \\
& & & \\
\hline \hline
\end{tabular}

\section{References}

Athreya, Kartik. 2006. "Fresh start or head start? Uniform bankruptcy exemptions and welfare." Journal of Economic Dynamics and Control, 30(11): 2051 - 2079.

Chatterjee, Satyajit, Dean Corbae, Makoto Nakajima, and Jose-Victor RíosRull. 2007. "A Quantitative Theory of Unsecured Consumer Credit with Risk of Default." Econometrica, 75(6): 1525-1589.

Stokey, Nancy L., Robert E. Lucas, and Edward C. Prescott. 1989. Recursive Methods in Economic Dynamics. Harvard University Press.

${ }^{*}$ Can be doubled for couples

${ }^{\dagger}$ Can be multiplied by 1.5 for couples

$\ddagger 33,000$ for couples 